Florida International University FIU Digital Commons

FIU Electronic Theses and Dissertations

University Graduate School

9-22-1997

\title{
Occupational stress in private schools: a teacher profile
}

John P. Davies

Florida International University

DOI: $10.25148 /$ etd.FI14062207

Follow this and additional works at: https://digitalcommons.fiu.edu/etd

Part of the Educational Leadership Commons

\section{Recommended Citation}

Davies, John P., "Occupational stress in private schools: a teacher profile" (1997). FIU Electronic Theses and Dissertations. 2741. https://digitalcommons.fiu.edu/etd/2741

This work is brought to you for free and open access by the University Graduate School at FIU Digital Commons. It has been accepted for inclusion in FIU Electronic Theses and Dissertations by an authorized administrator of FIU Digital Commons. For more information, please contact dcc@fiu.edu. 


\section{FLORIDA INTERNATIONAL UNIVERSITY \\ Miami, Florida}

OCCUPATIONAL STRESS IN PRIVATE SCHOOLS: A TEACHER PROFILE

A dissertation submitted in partial satisfaction of the

requirements for the degree of

DOCTOR OF EDUCATION

IN

EDUCATIONAL LEADERSHIP

by

John P. Davies 
To: Dean Ira Goldenberg College of Education

This dissertation, written by John P. Davies, and entitled Occupational Stress in Private Schools: A Teacher Profile, having been approved in respect to style and intellectual content, is referred to you for judgment.

We have read this dissertation and recommend that it be approved.

Peter Cistone

Joan Lutton

Paul Rendulic

Sarah Pell, Major Professor

Date of Defense: September 22, 1997

The dissertation of John P. Davies is approved.

Dean Ira Goldenberg

College of Education

Dr. Richard L. Campbell

Dean of Graduate Studies

Florida International University, 1997 
COPYRIGHT @ 1997 by John P. Davies

All rights reserved 
I dedicate this dissertation to Dr. Lorraine Gay. Her dedication to her subject was transcended only by her devotion to her students. 


\section{ACKNOWLEDGMENTS}

Learning is rarely a solitary endeavor. I express my sincerest appreciation to all of those persons who helped make this dissertation a reality, but equally important touched my graduate experience in important ways. Dr. Sarah Pell has been my advisor for eight years. I cannot begin to thank her for her support and reassurances over the years. Her classes provided a wonderful forum for thinking about some of the serious issues in education. My view of education today is due in no small measure to some of the ideas I tested in her classes over the years. To her I am also indebted for encouraging me in my research on media issues and education. I am profoundly grateful to Dr. Peter Cistone who helped me to understand that all educational enterprises are political. Through his presentations and class discussions I came to see leadership and organizations in a completely different light. Insights taken from his classes have forever altered the way I approach my professional life and I have never looked at schools the same way since for "There is less to rationality than meets the eye." Dr. Lorraine Gay spent literally hours on the phone with me discussing my dissertation from beginning to end. For me there is a special joy and sense of accomplishment that she was able to read it in its entirety and pronounce it a study of value before she passed on. When I arrived in Miami 11 years ago one of the first educators I met was Dr. Joan Lutton. Over the years 
she has become a good friend and mentor. I want to acknowledge her hard work in helping make this dissertation a reality. More importantly, I wish to thank her for helping me understand the world of private schools and the invaluable advice she has given me over the years.

This study would not have been possible without the cooperation of several individuals who encouraged the faculties at their schools to participate. I would like to express my appreciation to William Creeden, Dr. Charlie Clark, Bill Jablon, Ned Jaycocks, Joan Lutton, Gene Bratek, and Penny Riegelman.

Dr. Michael Fimian of Appalachian State University, who developed the Teacher Stress Inventory, could not have been more helpful. He encouraged this study from the beginning and offered counsel throughout the process.

I am also indebted to my friend and colleague, Diane Koch, who graciously proof read this manuscript.

Finally, I wish to thank my wife, Roxane. How do you thank someone for nine years of encouragement, support, and patience (I told her it would only take three years!). 


\author{
ABSTRACT OF THE DISSERTATION \\ by \\ John P. Davies \\ Florida International University, 1997 \\ Miami, Florida \\ Professor Sarah J. Pell, Major Professor
}

OCCUPATIONAL STRESS PRIVATE SCHOOLS: A TEACHER PROFILE

The purpose of this study was threefold. The primary purpose was to develop a stress profile for teachers in private schools. This study also addressed two exploratory issues. The first, consisted of an examination of the possible differences in the levels of on-the-job stress among teachers in different types of private schools. A second issue was to discuss the findings on private school in light of the extant literature on public schools, specifically using the data collected by Fimain to develop the Teacher Stress Inventory. This study was conducted utilizing 316 full time teachers from seven schools from six different states.

The instrument employed in this study was the Teacher Stress Inventory (TSI) developed by Fimian (1988). The TSI is a 10 factor, 49 item self-report measure. The 10 factors consist of five Stress Sources and five Stress 
measure. The 10 factors consist of five Stress Sources and five Stress Manifestations subscales. The mean for these 10 factors yields the stress construct termed "Total Stress." Of the 437 surveys mailed, 316 usable surveys, i.e., $72.3 \%$, were returned.

The results suggest that private school teachers experience moderate levels of stress. The mean score was 2.27 indicating a lower than average stress level as measured by the TSI. Comparisons between types of private schools revealed that there were no significant differences between the stress levels of teachers in boarding and nonboarding schools. Teachers in large schools experience significantly higher levels of stress than teachers in small and medium size schools. However, the measurable difference between them translates into a very small difference in terms of the real stress levels of these teachers in their professional lives. A significant difference was also found between the stress levels of public $(\underline{M}=2.60)$ and private school teachers $(\underline{M}=2.27)$. Both means fall within the moderate range, however, while private school teachers experience lower than average levels of stress, the stress levels of teachers in public schools falls in the higher than average range.

Recommendations for reducing stress levels in both private and public schools are presented as well as suggestions for future research. 
CHAPTER

PAGE

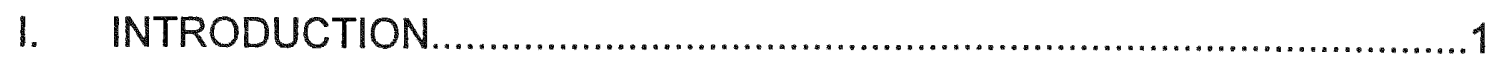

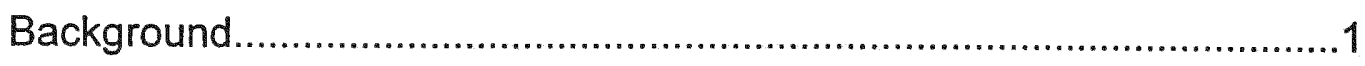

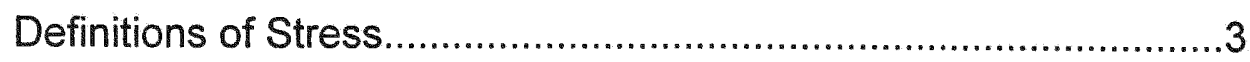

Sources of Teacher Stress...........................................................

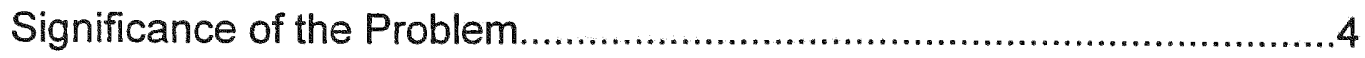

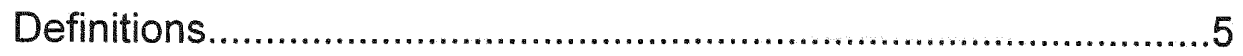

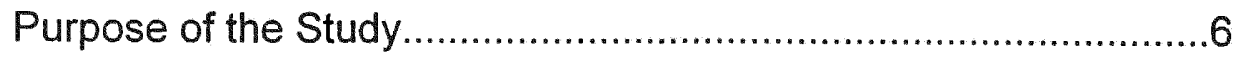

Statement of the Research Questions.............................................7

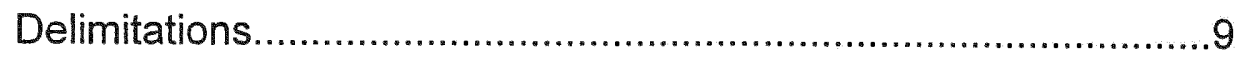

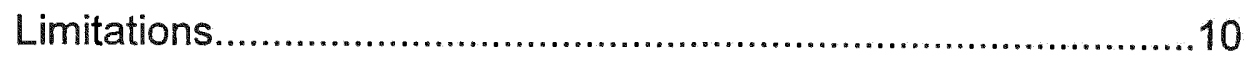

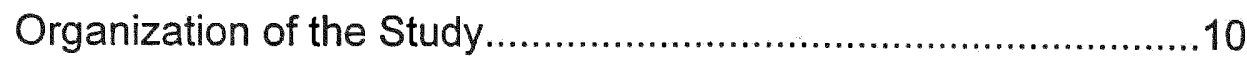

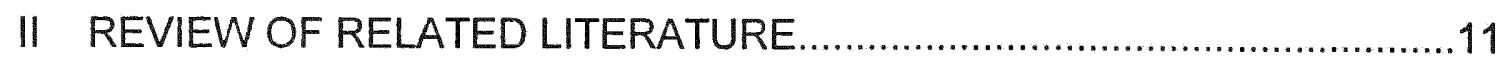

Stress: General Concepts..................................................................11

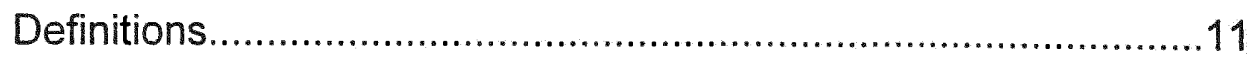

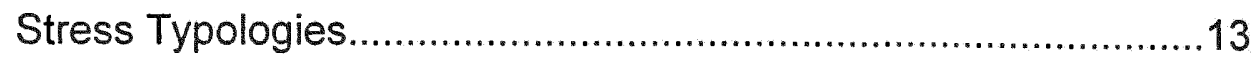

Descriptors of Stress in the Educational Setting.....................................14

Research by Teaching Populations.....................................................19 
Demographic Approaches to Stress Research.

Sources of Teacher Stress.............................................................22

Consequences of Teacher Stress....................................................30

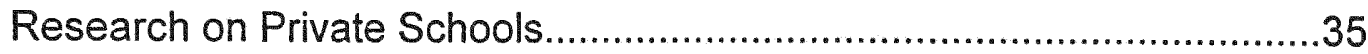

Literature Related to Research Questions........................................39

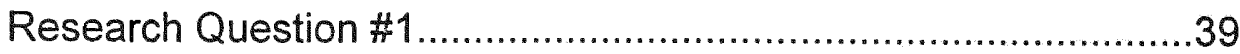

Research Question \#2 \#......................................................40

Research Question \#3......................................................41

Research Question \#4........................................................43

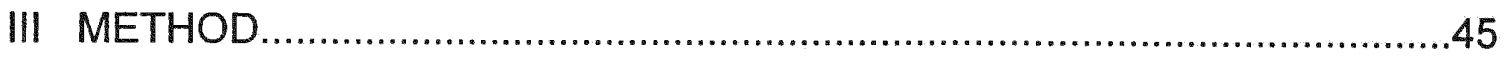

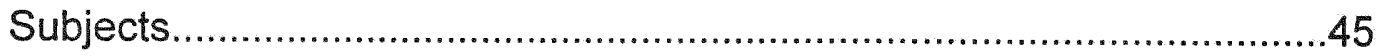

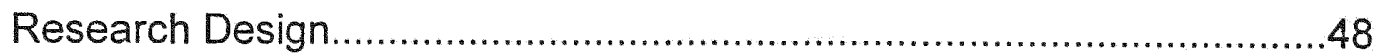

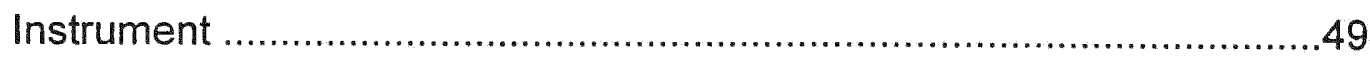

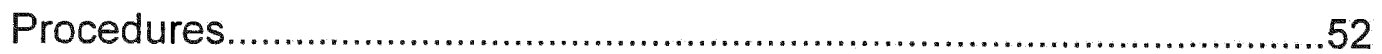

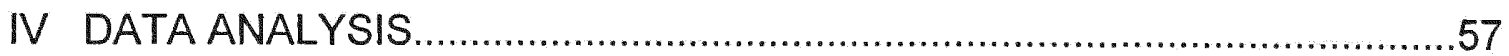

Stress Ratings by Factors: Stress Sources.....................................57

Stress Ratings by Factors: Stress Manifestations...............................59

Composite Score for Factors....................................................60

Analysis of Research Question \#1 \#..............................................60 
Analysis of Research Question \#2 \#...........................................61

Analysis of Research Question \#3............................................61

Analysis of Research Question \#4 \#............................................62

The Stress Profile of Private School Teachers...................................62

Profile: Factor Data......................................................63

Profile: Individual Item Data..................................................64

Comparative Analysis of Private Schools by Type and Size...............66

Boarding and Day Schools...............................................67

An Analysis of Schools by Size..........................................68

Comparative Analysis of Private and Public Schools.........................71

Comparison of TS/ factors and total stress strength.................71

Comparison of individual item means..................................73

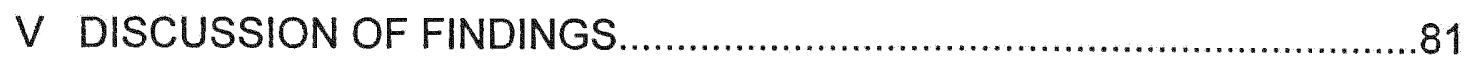

Research Question \#1: Stress Levels Based on Student Discipline and motivation.................................................................... 81

Research Question \#2: Stress Levels Based on Professional

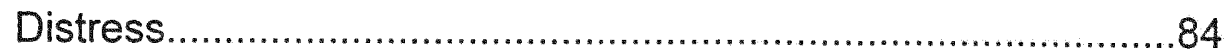

Research Question \#3: Stress Levels Based on Professional

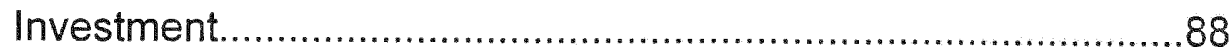


Research Question \#4: Stress Levels Based on Work-Related

Stress.

Discussion of Differences in Types of Schools.

Comparison of Private and Public Schools.

Recommendations for Managing Stress. 102

Recommendations for Future Research. 104

LIST OF REFERENCES 106

APPENDIX 


\section{CHAPTER 1}

Introduction

Occupational stress now represents a significant concern in the workplace. In recent decades research has begun to explore teacher stress. Despite a full range of literature on stress in public schools, very little attention has focused on job related stress in private schools. In an effort to address the shortfall of research in this area the major purpose of this study is to construct a profile of occupational stress among teachers in private schools. This profile will be developed using the Teacher Stress Inventory, an instrument designed specifically for measuring and evaluating on-the-job stress in teachers.

\section{Background and Significance of the Problem}

Teaching has been identified as a stressful profession. Addressing the National Education Association in 1979 then president William McGuire noted: "Mental and physical stress is driving thousands of teachers out of the classroom. Stress is leading to 'teacher burnout' and the problem threatens to reach hurricane force if it isn't checked soon" (cited in Cunningham, 1983, p. 38). More recently, Dedrick and Raschke (1990) have noted that job related stress has led as many as 50 percent of educators to seriously consider leaving the profession. Reflecting these educators' concerns, several educational organizations including the National Educational Association, The National Association of Secondary School Principals, Phi Delta Kappa, and the Council for Exceptional Children, have addressed teacher stress as a serious issue. Left to run its course without intervention stress can also lead to burnout. Among those concerns are not only the loss of teachers to the profession, but the mental 
and physical problems teachers experience as well as the negative impact on the delivery of instruction. Because of these negative factors considerable research on stress in schools has been conducted as well as the development of prescriptions and resources by various educational organizations for coping with teacher stress.

Despite the interest and attention devoted to the occupational stress of teachers (as well as administrators) very little attention has focused on the stress of teachers in private schools. The dearth of research in this area is perplexing given that a significant number of teachers are employed in the private sector. The National Association of Independent Schools (NAIS), the flagship of independent school organizations, for example, has over 1000 member schools enrolling over a 500,000 students. NAIS schools employ with over 46,000 teachers and another 8900 administrators. The National Center for Education Statistics (1993) counts 109,268 schools of which nearly a quarter are private. In total, these private schools employ over 350,00 teachers.

Not only do a significant number of teachers work in private schools, but two trends in education give every indication that private sector teachers will continue to be a growing presence on the educational horizon. First, the National Center for Education Statistics estimates that the number of private schools is growing- some $11 \%$ over the past decade. Second, there is some evidence to suggest that even some public schools may be undergoing a privatization of sorts. Vouchers continue to emerge on the political scene from time to time although the number of school districts experimenting with some variation of this system are limited. Murphy (1996), who has explored extensively the issue of privatization of education, suggests that educators who ignore this issue will be missing one of the major trends in schooling in the next 
century. One example of a privatization initiative is the charter school. By August of last year 25 states and the District of Columbia had passed laws regarding charter schools. Last summer the Miami Herald offered a "parents guide" to charter schools. The article noted that at that time 250 charter schools across the country had been established enrolling an estimated 60,00 students. A third of these schools were public schools (Potts, 1996). The most recent estimates from the Center for Education Reform put the number of charter schools nationally for the 1996-1997 school year at 480 with a total enrollment of 105,127 students. This represents a considerable rate of growth when one considers that the first charter school opened in 1992. With the number of educators already working in private schools and considerable evidence that the number will continue to grow, a fuller understanding of teacher stress in private schools is clearly warranted.

\section{Definitions of Stress}

The concept of stress is not new. Seyle, a pioneer in the development of our understanding of stress, notes that the ancient Greek physician, Hypocrites acknowledged that the body carried within itself its own restorative powers when exposed to pathogens. In the nineteenth century, Claude Bernard (1813-1878), a French physiologist, made a major contribution to the concept of stress when he pointed out that an important characteristic of all living organisms is that they maintain themselves within on a fairly constant basis despite changes in their external environment. Fifty years later, Walter B. Cannon, an American physiologist at Harvard, advanced the term homeostasis to describe the condition of constancy despite fluctuations in an organism's environment. He discussed the inner workings of the body in this effort to maintain inner stability. Cannon is also credited with identifying the stress response that would later be 
referred to as the "fight or flight" response when an organism is confronted with the stress of a threatening situation.

\section{Sources of Teacher Stress: An Overview}

One has only to look at the various inventories designed to measure teacher stress to see that the sources of teacher stress are numerous. For example, the Teaching Events Stress Inventory developed by Cichon and Koff (1980) numbers 36 items which have been identified as stressors for teachers.

Leading stressors identified by respondents in their research include involuntary transfer, managing disruptive children, report of unsatisfactory performance and threats of bodily injury. Another frequently cited cause of stress is the workload of teachers. Related to this workload is the size of classes. From a more global perspective the relatively poor image of teachers in society emerges as a source of stress as well. The results of Blase's $(1982,1984,1986)$ qualitative studies on teacher stress are engaging. Rather than identify potential stressors and have teachers rate them, he has allowed the sources of teacher stress to emerge from the teachers themselves. Among the sources teachers identify are lack of control of time, too many demands to meet adequately, jobs or responsibilities deemed unmeaningful or unchallenging by teachers, and threats to one's personal values (e.g., administrative request to change a grade).

\section{Significance of the Problem}

There are two issues that are relevant in terms of the development of a stress profile of teachers in private schools. The first issue revolves around concerns about the deleterious effects of teacher stress. On the one hand are concerns about how stress affects the individual teacher. Additionally, there are growing concerns about the negative impact teachers under stressful conditions may have on their schools. Kyriacou (1987) notes that worries about 
occupational stress and burnout in schools has now become international in scope for three reasons. First, there is a growing body of evidence that suggests that prolonged occupation stress can impair an individuals mental as well as physical well-being. A general interest in improving the quality of teachers' lives is a second reason. Finally, Kyriacou notes that the educational community is concerned that stress and burnout may significantly impair student/teacher relationships, the quality of teaching, as well as the level of commitment of teachers.

If occupational stress represents a significant concern to the educational community then some effort needs to be made to address the dearth of research regarding teacher stress in private schools. Presently some 350,00 teachers are pursuing their careers in nonpublic schools. If present trends continue this number will continue to grow. How does one account for the lack of research on this important segment of the teaching profession? It is not uncommon to hear a person remark that teaching in private in private schools is a lot easier because private schools do not have many of the same problems as their counterparts in the private sector. This conventional wisdom may sound convincing but it does not really tell us much about whether private schools represent stressful environments. If occupational stress in schools is a serious matter and has potentially negative consequences for both teacher and institution, then the development of a profile of teacher stress in private schools is clearly warranted. Definitions

1. Stress: Operationally defined in terms of the 10 factors identified as comprising teacher stress on the Teacher Stress Inventory. These factors fall within two general categories, i.e., sources or causes of stress and manifestations or symptoms. Sources of stress within this definition include: time 
management, work-related stressors, professional distress, discipline and motivation, and professional investment. The stress manifestations include: emotional, fatigue, cardiovascular, gastronomical, and behavioral.

Responses to each factor are based on a Likert scale with a rating of 1 for "No Strength" and 5 for "Major Strength." A total score of 3.29 or above indicates a "significantly strong" stress level. Moderate stress is indicated by a score between 1.94 and 3.27. A score of 1.93 or lower is indicative of a "significantly weak" stress level. In addition, response ranges for each individual subscale are provided in the TS/ manual as well.

2. Private school: educational institution with its own governance structure (board of trustees) which operates independently of the public school system. Private schools selected for this study were institutionally healthy, i.e., characterized by demonstrated leadership, sustained enrollments, and a sound financial situation. For the purposes of this study only member schools of the National Association of Independent Schools were selected. Proprietary or religiously affiliated schools do not fall within this definition.

\section{Purpose of the Study}

The purpose of this study was to construct a profile of occupational stress levels in teachers in private schools by collecting data using the Teacher Stress Inventory (TSI). Participating schools administered the instrument to approximately 350 teachers in a variety of private school settings. Data analysis was used to address three issues. What does stress "look like" in the private school? This TSI provides data on 10 different factors or subscales which have been identified specifically as related to stress in the educational environment. These factors were used to construct a profile of on-the-job stress in the private sector. Part of the development of this profile revolved around four research 
questions. Based on the sample population an analysis of the data allowed for the exploration of possible differences between stress levels in private schools based on variables such as school size, boarding and day schools. Finally, data findings were used to discuss private school stress in light of the extant literature on stress in public schools. Part of that discussion included a comparative analysis of the findings in this study with the data used to norm the TSI. This analysis was only of an exploratory nature, however, in light of the fact that the data collected to norm the TSI occurred before 1987.

\section{Research Questions}

1. What levels of stress do private school teachers experience in terms of student discipline and motivation?

Numerous studies indicate that student discipline and motivation are a significant source of stress for public school teachers (Cichon \& Koff, 1980; Feitler \& Tokar, 1980; Morris \& Morris, 1980; Abernathy, Manera, \& Wright, 1985, Blase, 1986; Young, 1989; Okebukola \& Jegede, 1982). Although few in number, the studies on private school stress do indicate that student discipline is a source of stress, but not to the degree as it is in public schools. A possible exception may be residential schools which Dey (1980) and Cohen (1980) suggest are particularly stressful. The selective admissions process of many private schools as well as the option of having students who present discipline problems or poor motivation withdraw should reduce the stress teachers experience. Solman and Feld's (1989) study of Catholic school teachers, for example, indicated that stress arising from discipline problems was present but substantially lowers than what their public school colleagues reported. How do diminished discipline problems and higher levels of student motivation translate into levels of stress among private school teachers on the TSI? 
2. What levels of on-the-job stress do private school teachers expereince in terms of personal distress, i.e., promotion opportunities, inadequate salary, status and respect, and recognition?

Esteve (1989) notes a number of factors related to status, respect, and recognition serve as secondary and environmental contributors to teacher stress including: confusion over the goals of education, increasing contradictions in the role of teachers, and a generally poor view of teachers in our present society. Salary, as well, has been identified as a source on stress in public schools (Kyriacou, 1987). Comparatively, salaries and benefits have historically been lower in private than in public schools which should be reflected in the stress of private school teachers.

3. What are the stress levels of private school teachers based on professional investment, i.e., classroom autonomy, opportunities to air personal opinions, opportunities for professional growth, intellectual/emotional stimulation?

In his study of the educational attitudes of private school teachers Cookson (1980) addressed some of the specific sources of stress in terms of teachers' professional investment. He found, for example that intellectual independence is one of the most important qualities that teachers and school heads valued. Cookson's study also suggested that private school teachers expect to have autonomy in the classroom and that school heads support that autonomy.

4. What are the stress levels expereinced by private school teachers in terms of of work-related stress, i.e., lack of time for preparation, pace of the school day, shortchanging of personal priorities in light of time demands? 
Role overload, time pressures, and large classes are all predictors of teacher stress in public schools (Manera \& Wright, 1980; Gupta, 1981; Needle, Griffin, \& Svendsen, 1981; Blase, 1986; Okebukola \& Jegede, 1992). Despite a dearth of research on private schools stress, one of the strongest similarities between public and private school teachers is the role they attribute to time pressures in terms of stress. In their comparative study of public and Catholic schools Solman and Feld (1989) found that teachers in both types of schools recorded time demands as their greatest stressor. Similarly, Pierce and Molloy's study of private school teachers indicated that teaching workload and time pressures served as the greatest sources of stress and in substantially greater numbers than public school teachers.

\section{Delimitations}

The teacher population for this study was limited to 316 teachers from private schools in major metropolitan areas. A return rate of $72.3 \%$ of the original surveys mailed was achieved. Schools with a religious affiliation were not included because they often operate within a larger organizational framework and represent a special kind of school culture. Similarly, proprietary schools, i.e., school privately owned an operated for profit, did not participate in the study.

In order to yield a sample population whose teaching responsibilities best represent the professional life of a private school teacher only individuals who worked full-time and whose primary responsibilities were teaching participated. Teachers participating in the study represented elementary, middle, and high school teachers from seven schools from six different states. Schools ranged in size from 180 to over 1100 students. All of the schools were coeducational and one school also contained a boarding program.

Limitations 
While efforts were made to include a single-sex school in the research population only coeducational schools are represented in the final data (see Chapter 3).

\section{Organization of the Study}

This study is divided into five chapters. The initial chapter presents the background and significance of the problem, definitions, as well as a conceptual overview of stress both generally and in the educational setting, and sources of teacher stress. In addition, the chapter details the purpose of the study, a statement of research questions, and limitations as well as delimitations of the study. Chapter 2 offers a review of the literature as it relates to stress in both the public and private sectors. Chapter 3 describes the research population, the research design, the rationale for instrument selection, and procedures. Chapter 4 presents an analysis of the of the data and Chapter 5 a discussion of the results, recommendations regarding stress management, and suggestions for future research. 


\section{CHAPTER 2}

\section{Review of Related Literature}

Stress is an important part of everyday life. While much of the attention given to stress has been negative, stress has a positive dimension as well. A number of experts argue that our world is becoming increasingly stressful. Alley (1980) suggests that the teaching profession is as well. Even twenty years ago Brodsky argued that teaching constituted one of the most stressful professions (cited in Phillips, 1982, p. 192). While interest in stress has been around since classical times, the experiences of those involved in combat during World War II and the Korean War accelerated this interest leading to a large body of literature that has developed in the last four decades. In the 1970 s interest in stress coincided with research on organizations and further extended this body of literature. These explorations on stress within an organizational framework were quickly translated into educational organizations as well.

\section{Definitions}

\section{Stress: General Concepts}

Today the term stress is understood in a number of different ways. Often the term is confused with related concepts such as anxiety or tension. At times there is a failure to make a distinction between the terms "stressor" and stress. Generally, stress has been approached from three different perspectives: stimulus, response, and transactional. The stimulus approach views stress as the experience of a specific type of stimuli. These stimuli are threatening or place demands on the individual. A limitation of this view is that stress is seen from the perspective of what a stressor does to the individual. Moreover, various stimuli are universalized and assumed to be stressful for all individuals. 
A second approach to this concept looks at stress from a response perspective. Seyle is a leading proponent of this understanding of stress. Here the attention is shifted away from the stressor and onto the person's biological or psychological response to the stressor. The name Seyle gave to an organism's response to stress is the General Adaptation Syndrome (GAS). He defines stress as "the nonspecific (that is, common) result of any demand upon the body, be the effect mental or somatic" (Seyle, 1982, p. 7). The GAS is a three stage process in which the initial response is the alarm reaction. During this phase the organism mobilizes its defenses to cope with the situation. The second phase, resistance, occurs because an organism cannot maintain the initial phase for a prolonged period of time. The third stage of the GAS may or may not occur. If an organism continues to experience a stressful situation without respite then exhaustion results. Related to this third stage is Maslach's (1982) work on burnout, a condition resulting from prolonged stressful situations. One of the characteristics identified by Maslach of burnout is emotional exhaustion.

Lazarus and Folkman (1985) have been instrumental in developing an alternative understanding of stress. Their work has led to a transactional view of stress that synthesizes the stimulus and response approaches. Here stress is conceived as a transaction between an individual and his or her environment. Initially, Lazarus and Folkman maintain the individual, when confronted with a stressor, makes a cognitive appraisal of the situation and evaluates to what extent the situation is stressful. Having determined the degree of stress the individual moves into a coping process in order to manage the demands of the person/environment relationship. "Psychological stress," then, "is a particular relationship between the person and the environment that is appraised by the 
person as taxing or exceeding his or her resources and endangering his or her well being" ( $p .19)$.

Not all stress is negative. Seyle (1976) makes a distinction between good and bad stress. He defined positive stress, which he termed "eustress," as "pleasant and curative." "Distress," or negative stress, he described as "unpleasant or disease-producing stress." Similarly, Lazarus (cited in Friesen, 1986, p. 6) distinguishes between challenging (positive) and threatening (negative)stress. All stress, whether distress or eustress, places demands on the individual and taps the body's resources (Seyle termed these resources as "adaptability reserve"). Eustress can produce some of the same biochemical reactions as distress. Because of its demands on the body's resources too much good stress can be harmful as well.

\section{Stress Typologies}

A number of typologies have been developed by stress experts to explain the various dimensions of stress, e.g., sources and consequences. Each contributes to a better understanding of the role that stress plays in the educational community. In terms of sources of stress four general sources have been identified: personal, interpersonal, institutional, and societal (Alley, 1980). Personal stress is "that which we do to ourselves--our inner fears, inner drives, ambitions, etc." (Alley, p. 7). Related to personal stress is the research conducted by Friedman, Meyer and Rosenman (1974) on personality type and stress. They found that individuals with Type A personalities have higher incidences of coronary problems. Fimian (1988) notes, however, that the actual link between personality and stress and burnout have yet to be adequately researched. Interpersonal sources of stress are concerned with how individuals react with one another. All interpersonal relationships are stressful Alley notes. 
The nature of the relationship, being in love as opposed to dealing with the illness of a loved one, can generate good or bad stress. Institutional stressors carry a myriad of forms. They are often related to interpersonal sources of stress, e.g., how one relates to a superior at work. Within the school setting institutional sources of stress for educators include school polices, mainstreamed student populations, and time management. A final source of stress is societal. According to Alley, these stressors range from inflation, traffic, and air pollution to media attacks on the public education system.

Just as the sources of stress have been identified, the consequences of stress have been as well. Generally, we respond to stress on two levels: physically and mentally. Stress has emerged as a major public health concern. And for good reason. Pelletier (cited in Goodall \& Brown, 1980, p. 18-19) notes that major medical textbooks now attribute from 50 to $80 \%$ of all diseases to psychosomatic or stress-related origins. Needle, Griffin, Svendsen and Berney (1980) suggest that individuals can respond to occupational stress on four levels: psychological, behavioral, physiological and somatic. Among the behavioral registers of stress are use of medications, alcohol, tobacco products and fluctuations in appetite. Somatic effects include headaches, dizziness, abdominal pains, insomnia and fatigue. Job dissatisfaction, anxiety, tension, irritability and depression are manifestations of the psychological effects of stress.

\section{Descriptors of Stress in the Educational Setting}

Turk, Meeks, and Turk (1982) note that from an educational perspective the term "teacher stress" is relatively new, but the concept has appeared on a regular basis since 1933 under such labels as "teacher anxiety," teacher morale," "teacher problems" and "teacher burnout." They point out that although 
the terms are not identical, they all point to the same issue, i.e., schools present themselves with situations and pressures that are stressful. Typically, stress is understood in a pejorative way. Needle, Griffin, and Svendsen (1981) define teacher stress as "discrepancies between work values and occupational rewards available from the school environment" (p. 176). In conceptualizing teacher stress Bensky, Shaw, Gouse, Bates, Dixon, and Beane (1988) employ a discrepancy framework as well.

One of the foremost authorities on teacher stress writes that stress, "refers to the experience by teachers of unpleasant emotions such as anger, tension, frustration, anxiety, depression and nervousness, resulting from aspects of their work as teachers" (Kyriacou, 1989, p. 27). Litt and Turk (1985) describe teacher stress as "the experience by teachers of unpleasant, negative emotions and distress that exists when the problems confronting teachers threaten their well-being, and surpass their ability to resolve these problems" (p. 178). Gupta (1981) notes that teacher stress is "the potentially dysfunctional responses of the individual (i.e., the teacher) to the demands of the work place (i.e., the school" (p. 4). A departure from a negative view of teacher stress is Maples' (1980) reminder that stress has positive dimensions. While admitting that stress is a serious educational concern, she emphasizes that stress is a fact of life and can be framed positively as a challenge and managed successfully. When approached from this perspective by teachers it can serve as "a thriving force in their lives."

A more novel approach to stress in education has been presented by Speck (1993) who has suggested that it should be understood as ethical conflict. While he does not discount environmental factors, Speck notes that: "Malignant stress--stress that results in personal dysfunction--is caused by dissonance in 
personal perceptions of how people and organizations ought to perform, perceptions that are often grounded in faulty notions of how people and organizations operate" (p. 34). He argues that these perceptions are value judgments rooted in the way educators understand what life is. Elsewhere he writes:

Imposing values is at the heart of stress because the individual has decided to cast reality in the image of his or her values. If the individual does not have the resources to make reality into that image and persists in believing reality should be made into that image, malignant stress could be at work. I say "could be" because a person may make values statements without understanding their ramifications (p. 35).

The stress cycle developed by Friesen comes directly out of his work with stress among teachers and administrators. His model consists of four elements. In some respects it combines the views of Seyle with those of Lazarus and Folkman to create a model of the stress cycle that accounts for the importance of both the stimulus and response as well as the cognitive dimension. In addition, it provides an excellent model for interpreting some of the results of this study in a later chapter. The first element in the cycle is the stressor which can be any stimulus that makes demands on the individual. The second element is the resources that an individual possess. An imbalance occurs if the resources the individual has are inadequate to meet the demand. The third element of the cycle is the response of the individual to the stress. The response may be adaptive or maladaptive, depending on the individual. If the response is maladaptive a final element of the cycle is the consequences of this response. An example of this sort of negative response to stress is burnout. In addition, 
Friesen offers several noteworthy general observations about stress in light of his model of the stress cycle that contribute to our understanding of the dynamics of stress:

Stressors do not necessarily cause stress. It is the perceptions about the imbalance between demands and resources, and the perceived seriousness of the consequences of failure that cause the stress response. Stressors are always present among people. At different stages of life different stressors become more important for people. The perceptions of the demands made on an individual by a stressor is an important aspect of what happens in the stress cycle. The perception of an individual's coping abilities (resources) is another key element in the stress cycle. The cognitive and behavioral responses that an individual makes in response to stress is a major element in determining the effect stress will have on the individual (p. 10).

Freisen also notes that individuals with poor coping skills run the risk of experiencing burnout.

Burnout may take several forms depending on the perceptions of demands, resources and consequences of failure. Cognitive and behavioral responses are significant determiners of what happens. Finally, it is the individual who creates stress and has to deal with it. Veninga and Spradley (1981.32) state that "high stress perceivers will...burnout out more easily." As a consequence coping skills (or life skills) appear to lie at the heart of a stress management program (p. 10-11). 
Collectively, the research suggests a model for teacher stress with four basic components. The first is the particular stressor. The second element is the teacher's perception or cognitive appraisal of the situation. Interconnected with perception are the resources that the individual teacher possesses to deal with the stress. Finally, perception, combined with personal resources determine the teacher's response to the stressor. This response may be adaptive or maladaptive. A maladaptive response might very well create a feedback loop in which the original stressor(s) affect perception and resources adversely creating further debilitating stress which creates a downward cycle and perhaps resulting in burnout without intervention

Stress and burnout are often confused. Fimain (1988) notes that while these two concepts are related they are not the same. This condition results from prolonged stressful situations. Maslach (1982), who has conducted considerable research on burnout, and has developed a measure for this condition maintains that it is characterized by emotional exhaustion, depersonalization, and reduced personal accomplishment.

The number of publications, several by educational organizations, designed to help teacher cope with stress and burnout attests to the level of concern in education today (Roberson \& Rich, 1993; Greer \& Greer, 1992; Dedrick \& Raschke, 1990; Swick, 1989; Washington, 1989, Cole \& Walker, 1989; Alschuler, Carl, Leslie, Schweiger, \& Uustal, 1984; Cedoline, 1982; Shaw, Bensky, \& Dixon, 1981, Truch, 1980; Miller, 1979). In addition, several instruments, developed solely for measuring teacher stress have been developed: Teacher Stress Inventory (Fimian, 1988), Teacher Stress Inventory, a qualitative measure developed by Blase (1986), Wilson Stress Profile for Teachers (Wilson, 1979); The Teaching Events Stress Inventory (Cichon \& Koff, 
1980) and the Teacher-Event Stress Inventory developed by Pratt (1978). Also extant in the literature is a variation of Cichon and Koff's inventory created to by the Tacoma, Washington public school district, the first district to implement a comprehensive program of stress reduction that actually included insurance coverage for teachers suffering long-term disability as a result of classroom stress or burnout (Young, 1983). Okebukola and Jegede (1992) have developed a Science Teacher Stress Inventory. Finally, Manera and Wright (1980) developed a Q-Sort ranking instrument for measuring stress in teachers and administrators.

It is important to note that despite a high level of concern there is not total agreement over stress and burnout. This is complicated by the fact that there is no widely accepted objective measure of stress (Kyriacou, 1989). DeMoulin (1991) suggests, for example, that the term "burnout" is used inappropriately and is not as widespread as it believed. He acknowledges high levels of stress and argues that there is a tendency to elevate stress levels to burnout status. Similarly, Iwanicki (1983) maintains that burnout must be diagnosed cautiously, noting that there are degrees of burnout, and it is not unusual for teachers to experience occasional feelings of mild to moderate burnout. An intriguing observation has been made by Cox and Brockley (1984) who suggest that because teachers are a very articulate occupational group they may be better able to define and discuss their feelings and perceptions of work thus giving the appearance of experiencing and reporting more stress!

\section{Research by Teaching Populations}

One approach in the research on occupational stress in teachers has been to study a particular segment of the teaching population. Some of the 
earliest research, beginning in 1950 focused on novice teachers. Purkerson (1980), Morris and Morris (1980), and Abernathy, Manera and Wright (1985) have explored stress in student teachers. Surveying three decades of research on inservice and student teachers, Morris and Morris found four major areas of stress among this population: student behavior, relationships with supervising teachers and university supervisors, self-adequacy, and learner achievement. Abernathy, Manera, and Wright found that student teachers ranked classroom discipline and unmotivated students as the two greatest stressors. An interesting finding in their study- student teachers and their cooperating teachers ranked 13 stress factors nearly the same!

Considerable attention has focused on the impact of Public Law 94-142 on education. Not surprisingly then, special educators have been the subject of several studies (Billingsley \& Cross, 1993; Greer \& Greer, 1992; Dedrick \& Raschke, 1990; Zacherman, 1983; Fimian, 1982). In some cases researchers have been interested in teachers of a particular subject. Okebukola and Jegeded (1992) examined the stress factors and coping strategies of science teachers while Hamann (1990) explored stress in master music teachers. Other specific teaching groups receiving attention include experienced high school teachers (Litt \& Turk, 1985), secondary teachers (Capel, 1989), teachers undergoing classroom appraisal visits tied to pay raises and job retention (Roberson \& Rich, 1993), and preschool teachers and child care workers (Manlove, 1994). Washington (1989) and Dworkin (1987) researched stress levels in urban teachers, while Farber (1984) examined stress in teachers working in suburban schools. 


\section{Demographic Approaches to Stress Research}

Another avenue of research has been to examine stress and burnout along demographic lines such as age, gender, grade level, and years of teaching experience (Borg \& Riding, 1991; Malick, Mueller, \& Meinke, 1991; Bryne, 1991; Solman \& Feld, 1989; Fimian, 1988; Faber, 1984; Feitler \& Tokar; 1983; Mclntyre, 1982). The demographic approach has yielded varying results. Farber's (1984) study of suburban teachers revealed that younger and middleaged teachers perceived themselves to be more burned out and less committed to the profession than older teachers. Feitler and Tokar (1980) found that teachers in the 31-44 age range reported higher levels of stress than either teachers under 30 or those 45 years and older. Solman and Feld (1989) found older teachers more stressed by the demands of a changing curriculum. Bryne (1991) found male high school teachers experienced higher levels of depersonalization (a characteristic of burnout) than females. His study also indicated that those working with middle and junior high levels students felt more stressed. Feitler and Tokar (1980) reported similar findings. In their study of teacher burnout Schwab and Iwanicki (1982b) found younger teachers reported that they experienced more intense feelings of emotional exhaustion and high school teachers reported that they accomplished less in their profession than middle and elementary school teachers. Malik, Mueller, and Meinke (1991) found higher stress levels among teachers than the lower grade levels. Schwab and Iwanicki (1982b) explored the relationship between Maslach's categories of burnout indicators and a number of variables including gender, educational level, grade level taught, and years of experience. In terms of depersonalization they 
found males have more frequent and intense negative feelings towards their students than females. Gupta and Douglas (1981) found that female teachers reported higher levels of role related stress. Similarly, Calabrese and Anderson (1986) noted higher stress levels among female teachers attributing these elevated levels to role conflicts and coping with a male-dominated environment. Both Gupta and Calabrese and Anderson suggest that the additional responsibilities of women who have more non-work demands in the home contributes to these gender differences. Using the TS/ Fimian (1983) found little actual relationship between gender and teacher stress levels and only a limited relationship in terms of teacher age. Additionally, he concluded that level of education bore little relationship to teacher stress levels as well. The work of Friesen and Richards (1984) on stress in Canadian teachers and principals supports Fimian's findings. Using a much larger sample population than Gupta and Calabrese and Anderson, Friesen and Richards found no significant differences in stress levels in males and females. Other background variables such as years of teaching experience, grade level taught, years of education, and size and location of the school failed to account for any significant amounts of teacher stress as well.

\section{Sources of Teacher Stress}

A number of factors have been identified as sources of teacher stress. Surveying the literature Okebukola and Jegede (1992) have identified the most frequently cited stressors for teachers as: poor working conditions, student misbehavior, insufficient teaching resources, overload of teaching duties, and students' poor attitudes toward work. To this list Kyriacou (1987) adds time pressure, low status, and conflict with colleagues. As noted previously, Needle, 
Griffin, and Svendsen (1981) conceptualized teacher stress as "discrepancies between work values and occupational rewards available from the school environment (p. 176). Insufficient time, less than desirable salaries and job security constituted the major sources of discrepancy in their study.

Cichon and Koff (1980) developed the Teaching Stress Events Inventory (TSEI) to study stress in a major metropolitan school district. Teachers ranked 36 events identified as stressful. Their results revealed that the five highest ranked items in descending order were: being involuntarily transferred, managing "disruptive" children, notification of unsatisfactory performance, being threatened with personal injury, and overcrowded classrooms. Least stressful events included dealing with students whose primary language is not English, teacherparent conferences, and being voluntarily transferred. Cichon and Koff's findings on student discipline as a major source of stress in the teaching profession are echoed in other studies as well. Feitler and Tokar (1980) surveyed 3,300 K-12 public school teachers. Over half of those surveyed (58\%) ranked "individual pupils who continually misbehave" as the number one cause of job-related stress. In their study of student teachers and stress Abernathy, Manera and Wright reported that "Classroom Discipline" was the greatest stress-producing factor for these teachers. In his study of the Tacoma, Washington School District Young (1989), using a modified version of the Teaching Events Stress Inventory, found that managing "disruptive" children was the most often reported source of stress. Borg and Riding (1991) suggest that "pupil misbehavior" may be a cross-cultural phenomenon in terms of teacher stress. Their study of secondary teachers in Malta revealed that students who misbehave are a significant source of stress for them. In his study of primary school teachers in New Zealand Dewe (1986) reported similar findings regarding student discipline. 
Student discipline does not appear in all studies as a major source of stress. Litt and Turk (1985) in the research on sources of stress and dissatisfaction in experienced high school teacher did not find pupil misbehavior to be a factor. Farber (1984) examined stress and burnout in suburban teachers. He did not find that student discipline was a prime concern of these teachers.

In one of the few qualitative studies on teacher stress to date Blase (1986) used several stress related themes from the literature. Among stressors grouped under organizational factors by Blase that teachers identified were: lack of time, paperwork, lack of materials, and extra duties. Teachers also cited students as a significant sources of stress including discipline, apathy, and low achievement. After organizational and student factors, teachers named administrators as the third highest source of stress. Subcategorizes precipitating stress here included unclear expectations, lack of knowledge or expertise, lack of support, and inconsistency among others.

Legislation of an educational nature may serve as a powerful stressor to teachers. Based on the research of Bensky et al. (1988) and Dedrick and Raschke (1990) the passage of Public Law 94-142 seems to have contributed to the stress of teachers. The Education for All Handicapped Children Act of 1975 generates stress both at a compliance level as well as for teachers who are charged with carrying out its prescriptions but who don't feel that their superiors take the law seriously enough.

Over half of the states have legislated career ladder incentive programs. Many of these programs carry with them classroom appraisal visits. Roberson and Rich's study (1989) of teachers in Texas revealed that these appraisals generated considerable stress for teachers undergoing these evaluations. Their 
findings reflect the larger issue of evaluation as reflected in Cichon and Koff's (1980) study in which notification of unsatisfactory performance ranked third out of 36 stressors

Another identified sources of stress is the school's physical environment. Connors (1983) maintains that the design environment of educational institutions contributes to teacher stress. Borrowing from Zimring's conceptualization of stress as resulting from the dynamic interactions of persons and environment Connors suggest that school environments may have both a direct and indirect effect on stress. He notes that light levels, acoustic qualities, the arrangement of learning spaces, and the size of areas potentially contribute to stress by either facilitating or impeding user goals. On another level Connors reasons that the manner in which the environment is designed may indirectly impact on social interaction making it easier or more difficult.

Starnaman and Miller (1992), in their work on communication and burnout, argue that teacher participation in decision making can significantly reduce stress. Gupta (1981) as well sees a link between stress and decision making. "The burden of decision-making can occasionally be stressful. On the other hand, decision-making authority can minimize the adverse effects of other stress." She continues, "For instance, if the teacher has autonomy, she/he can resolve the conflicts or ambiguities inherent in the job" (p. 9). In a related vein, there is evidence to suggest that teachers who see themselves in control of their lives' circumstances (locus of control) are less likely to experience stress (Mclntyre, 1982; Kyriacou \& Sutcliffe, 1978).

Lack of opportunities for advancement and salary have been reported to be sources of stress for teachers. Both Kyriacou (1987) and Turk, Meeks, and Turk (1982) conducted extensive reviews of the literature on teacher stress. 
Both studies noted that inadequate salary emerged as a contributing factor to teacher stress. Goodhall and Brown (1980) report that lack of financial reward is a stress-producing factor frequently cited by teacher groups. They suggest that the demand for additional compensation may be partially regarded as a desire to be reassured of the value of the profession.

Regarding the lack of advancement opportunities, Farber (1984) found this to be a significant source of stress in suburban teachers. Calabrese and Anderson (1986) have suggested that "lack of perceived opportunity" among female teachers may elevate stress levels in female teachers. Focusing only on opportunities for promotion may be only half the equation, however. Writing on teacher burnout and the problems of advancement Cunningham (1983) observes:

Teachers are not respected within the profession: Prestige, honor, and money all go to the person who seldom sees a child. Many competent career-mined teachers, aware that the main opportunity for making status gains in education rests in full-time administrative positions, choose to leave the classroom. However, most teachers enter teaching because they enjoy working with students and like to be involved in planning curricular and instructional strategy. Such teachers are frustrated by existing promotional channels which do not provide incentives that reinforce teaching as a career but do reinforce administration (p. 42).

There are varying typologies reflected in the literature on teacher stress. One approach has been to examine stress along three lines: society, organization, and role-related. Describing societal sources (sometimes referred to as extra-organizational) of stress Iwanicki (1983) writes: 
The poor image of education is a major source of teacher distress for at least two reasons. First, it has led to diminished levels for those in the teaching profession. Second, it has prompted demands for increased productivity at a time when the financial support for education is being curtailed. It is not unusual for a burned-out teachers leaving education to comment "I gave it all I had, and they told me I needed to do a better job, they gave me more students, cut out my aid, and reduced my instructional materials and supplies allotment." (p. 28).

From a broader perspective Esteve (1987) in discussing the conditions of stress surrounding teachers notes that social changes have left teachers ill prepared and confused, thus adding to their stress. Like Iwanicki, he observes that in recent years the demands on teachers to accept new responsibilities has been increasing. Simultaneously a withdrawal from educational responsibilities by the community and particularly the family has transpired. This increase in responsibilities has not been accompanied by the necessary changes in teacher preparation to help them cope with these new demands. "The means which teachers have at their disposal have similarly remained unchanged and administrations have not made the necessary changes within their structures to adapt to the new circumstances. As a result," Esteve points out, " an increase in confusion about exactly what it is that teachers are supposed to be able to do and about the wide-ranging and complex role that society has entrusted to them" (p. 8).

Organizational sources of stress in the educational setting are abundant in the literature. These sources include bureaucracy, communication, work relationships, career development and promotion opportunities, supervision, and 
teacher implementation of educational programs within organizational constraints beyond their influence (Milstein \& Golaszewski, 1985; Iwanicki, 1983;

Bacharach, Bauer, \& Conley, 1986; Cedoline, 1982).

Finally, considerable research has examined the idea of role-related stress. As a stress factor, role has been conceptualized in several ways: role overload, role conflict, and role ambiguity. To this list Gupta (1981a) adds role underload and role insufficiency. "Role overload refers to having too much work to do in the time available, or having work that is too difficult for the skills and abilities a teacher has" (Gupta, 1981, p. 7). Teacher reports of role overload include too many preparations or back-to-back classes with no break. Manera and Wright (1980) found that teachers and administrators reported time management as the number one stressor in a 14 item survey of causes of teacher stress. Conversely, role underload results "when the teacher has skills and abilities that were acquired through experience (or in school) that are not being used on the job" (p. 9). Teaching out of field is an example of role underload. Role conflict includes teacher conflicts with administrators, fellow teachers, and the community. (See for example: Blase, 1984; Dederick \& Raschke, 1990). Role ambiguity is understood as "the lack of clear, consistent information regarding rights, duties, and responsibilities of a person's occupation and how they can be best performed (Schwab \& Iwanicki, 1982a, p. 62). Studies by Schwab and Iwanicki as well as Bacharach, Bamberger, and Mitchell (1990) and Pierson (1983) point to role ambiguity as a contributor to teacher stress. Role insufficiency results when teachers are not provided with the resources such as information and materials to do the job properly. This condition may result from a shortage of desks or books or the absence of a prescribed curriculum. 
Social support emerges from the literature as a source of occupational stress among teachers as well. Sarros and Sarros' (1992) study of social support and burnout revealed that those who enjoyed support from their principals had lower levels of emotional exhaustion burnout. Social support may aggravate burnout when sharing negative work experiences has the opposite of a therapeutic effect. Schwab, Jackson, and Schuler (1986) report similar findings in terms of the absence of social support networks as a contributor to burnout. In his study employing the TS/ Courtney (1988) found lower levels of stress among those teachers who enjoyed administrative support. He also found a link between principals management styles and stress levels of teachers.

Summarizing the results of her study on the importance of administrative support Gupta (1981) writes:

The school principal and other school administrators are critical in determining whether the work lives of teachers are stressful or not. In our study, the school principal emerged as one of the most critical influences on whether or not teachers experienced stress. Characteristics of supervisors and principals that are associated with stress include: making unilateral decisions delegating work to subordinates, but not the authority to do the work properly; caring only about the performance of subordinates and not their socioemotional needs; being overly critical; and not going 'to bat' for subordinates (p. 10).

Finally, Kyriacou's (1987) comments on the sources of stress in education point to a more general dynamic at work which may explain why teaching is now regarded as such a stressful profession. 
The main sources of stress for any individual teacher or generally for staff in any particular school varies greatly. Overall it is perhaps the general level of alertness and vigilance required by teachers in meeting the potentially threatening variety of demands made upon them that constitutes the essence of why the experience of stress and burnout is so prevalent (p. 148).

\section{Consequences of Teacher Stress}

Reporting on a Chicago teachers union survey Walsh (1979) began by announcing that practicing their profession may be hazardous to teachers' health. She noted that of the 5500 teachers who responded to the survey over $56 \%$ claimed they had experienced physical or mental health problems as a direct result of their jobs. Walsh went on to suggest that a major cause of teacher turnover was burnout, a condition resulting from prolonged stress. Walsh's comment reflect a broader concern about the negative effects of occupational stress in modern society. Matteson and Ivancevich $(1982 ; 1987)$, experts on occupational stress and management have developed an organizational framework for understanding work site stress. They have identified three general categories for stress outcomes: physiological, psychological, and behavioral. Among the physiological conditions they identify are changes in blood pressure, heart rate, and immunosuppressors.

Dissatisfaction, lowered morale, and apathy are psychological outcomes. Behavioral manifestations include decreased effort and attention span, as well as irritability.

According to Matteson and Ivancevich these outcomes of work related stress have two types of consequences: health/family and job performance. 
Estimates of loss to industry due to stress related illnesses are as high as $\$ 60$ billion annually (Matteson \& Ivancevich, 1982, p. 49). Among the illnesses which are stress related are hypertension, arteriosclerosis, ulcers, diabetes, headaches, and coronary heart disease. From the perspective of mental health they count depression, anxiety, nervous exhaustion, disorientation, feelings of inadequacy, loss of self-esteem, lowered tolerance for ambiguity, loss of achievement motivation, and increased irritability. When stress is translated into on-the-job performance these costs to the educational process can be considerable. Absenteeism, turnover, accidents and reduced decision-making effectiveness are some of the consequences of this stress in terms of performance.

The number of studies examining the causes of stress and providing measures on the level of teacher stress are legion. Comparatively, the research on the consequences of teacher stress are not so abundant. With some exceptions, the trend seems to begin with the assumption that chronic stress in teachers is bad for the individual and his or her school and then proceed to examine either the sources or degree of stress.

As reflected in the work of Matteson and Ivancevich concerns about the mental and physical well being of teachers are twofold. First, and most obviously is the well being of the individual teacher. Secondly, is the relationship between the teacher and the school, particularly students. Teachers experiencing stress related problems will carry these issues into their classrooms, faculty lounges and meetings, and their preparations. Blase (1986) has coined the term Performance Adaptation Syndrome (PAS) to describe the maladaptive cognitive and behavioral ways teachers respond to stress and the way its affects their instructional performance. 
In his study Blase (1986) found that teachers under chronic work stress reflected the PAS in several ways. Of particular importance among his findings was that teacher perceived stressors as interfering with instruction. Teachers reported that dealing with student discipline, student apathy, student absences, large classes, and extracurricular activities took away from instructional time. Blase also found that stressors requiring extra work led teachers to assign "busy work" or give less homework which either went uncorrected or corrected mechanically without the appropriate feedback.

A complimentary issue noted by Blase was that stress undermines teachers' intellectual curiosity and dampens their enthusiasm for their subject. Blase shares some particularly poignant comments from one of the respondents in his study.

When I first started teaching I was excited...I would try all kinds of things to make the class interesting. I was learning, growing myself...Teaching drains you! I've lost a lot of my enthusiasm for the subject. It's hard to keep up a facade of excitement when so many kids and parents don't give a damn about education (p. 32). Still, a third stress related issue that affects instruction is the issue of control. Blase found that in an effort to acclimate themselves to school related demands teachers often become overly concerned with the control and routine of their own behaviors and those of their students. As a result teachers factor control into their planning. "In anticipation of student discipline problems, for example, teachers develop lesson plans (i.e., materials, questioning techniques, objectives) with more concern for controlling students than for developing stimulating and meaningfully engaging learning experiences (p. 32). A connection also emerges between stress and the use of "rote and recitation" 
pedagogy. Teachers who are stressed interact differently with students according to Blase. These teachers report that they are less tolerant, less patient, less caring, and less involved while under stress. Each of these conditions has implications for the quality of instruction in the classroom of teachers who are continually experiencing stress.

Gupta (1981) points out that stress among teachers leads to dysfunctional behaviors such as reduced efficiency, tardiness, absenteeism, and turnover, which are not only expensive, but also disrupt the smooth functioning of the school. She notes that classes frequently taught by substitute teachers are less conducive to learning.

As noted earlier, stress is a concern because it poses health problems for teachers. Cichon, Koff, and Kotsakis, et al. (cited in Needle, Griffin and Svendsen, 1981, p. 178) found that more than half of the teachers in their study reported physical illness that they believed was work related. Fimain, Zacherman, and McHardy (1985) found that the use of both over-the-counter and prescription drugs as well as alcohol were related to on-the-job stress in teachers. In his research Fimian found that psychosomatic disorders such as stomach acid, cramps, racing heart, headaches, physical exhaustion are related to teacher stress. When teacher reports of these disorders were inspected in light of reported stress levels two consistent relationships emerged. Those teachers under stress reported more frequent disorders of this type than did those under less stress and teachers who experienced frequent psychosomatic disorders were generally under significantly more stress than those teachers who did not report symptoms (unpublished manuscript by Fimian reported in Fimain, 1988$, p. $72-73)$. 
In their study on stress related health problems of teachers Needle, Griffin, and Svendsen (1981) found that educators reporting higher stress levels also reported lower general well being, i.e., depression and anxiety. They also found a correlation between elevated stress levels and somatic conditions such as stomach and back pain, headaches and fatigue. The most common symptom reported by teachers in the United Kingdom in Kyriacou and Sutcliffe's (1978) study was exhaustion. Fimain and Krupicka (1987) explored the relationship between teacher stress and counseling. Those teacher who reported higher levels of Professional Distress (measured on the TSI by opportunities to air opinions, control over decision making, emotional and intellectual stimulation, and opportunities for improvement) were more likely to seek counseling for work related problems. Moreover, those teachers seeking out counseling also recorded stronger stress manifestations.

Teaching is an anxious profession (Phillips, 1982). In his study, When Teachers Face Themselves (1955) Jersild devoted an entire chapter to this condition. He argued that anxiety should be considered a key concept in education both from the perspective of the teacher as well as the student. "Anxiety can be described as a state of distress, uneasiness, disorder, or disturbance arising from some kind of stress within the personality" (p. 27). Regarding anxiety, he relates that in his discussion groups with teachers they demonstrated a desire to express themselves on this topic more than any other. Jerslid is decidedly psychoanalytic in his treatment of anxiety and explores the anxious condition of the child in the classroom as much as the teacher. Two of the sources of anxiety Jerslid identified for teachers were dealing with "difficult" children and the discrepancy between the real and idealized selves. 
Finally, some data, in addition to the work of Needle, Griffin, and Svendsen (1981), is available on the effects of stress on the well-being of private school teachers which will be discussed below.

\section{Research Findings on Private Schools}

Very little research has been conducted on occupational stress in private schools. Two of the most extensive studies were conducted abroad. Solman and Feld (1989) examined teacher stress in 82 Catholic schools in New South Wales. They compiled responses of those teachers who identified various factors as causing "much" and "extreme" stress and compared them with data from a similar study conducted on public schools in the same school district. The teachers in Catholic schools generally perceived their teaching jobs as less stressful and more satisfying than their public school counterparts. Respondents from both types of schools, however, held similar rankings in terms of what stressed them the most. Both the Catholic and public school teachers ranked time issues at the top of their lists. Responding to "Lack of time for preparation, marking, and/or organisation," $40 \%$ of the Catholic and $46 \%$ of the public school teachers indicated this caused them "much" or "extreme" stress. To "Lack of time to prepare adequately and/or to assist with individual pupil difficulties" Catholic and public school teachers responded $32 \%$ and $38 \%$ respectively. Similarly, when asked about "Excessive time demands of teaching and/or organizational duties" $41 \%$ of public and $35 \%$ of Catholic school teachers rated this as a source of considerable stress.

Student discipline emerged as the second highest factor in terms of stress for both groups. However, public school teachers generally found this to be more of a problem. For example, $22 \%$ of the Catholic and $36 \%$ of the public 
school teachers rated "Individual pupils who continuously misbehave as a source of "much" or "extreme" stress. When asked to respond to the statement, "Maintaining class discipline with difficult classes," $24 \%$ of the Catholic school teachers and $42 \%$ of the public school teachers identified this experience as very stressful. And while a significant percentage of Catholic school teachers rated "Impolite and disruptive behavior" as a source of considerable stress, this percentage increases to $32 \%$ among public school teachers surveyed. Other factors of note which generated "much" or "extreme" stress among Catholic teachers were problems with the school administration and/or staff $(19 \%)$, low involvement in decision making (14\%), and shortages of equipment and money $(16 \%)$.

Solman and Feld also examined the general well-being of Catholic school teachers using the General Health Questionnaire (GHQ). Again, comparisons with public school teachers were possible because of data collection in a similar study. Solman and Feld made an additional comparison with the results of a study conducted with other technical and professional workers which produced some interesting findings. Respondents can fall into one of three "disturbance" categories: "none," "mild," and "high." Those with a high disturbance rating will probably need the intervention of a trained health professional. Catholic school teachers recorded the same high levels of minor neurotic disturbance as their public school colleagues. Among Catholic school teachers $36 \%$ of the females and $30 \%$ of the males scored in the "high" category. The percentage of male and female public school teachers in the "high" category were $35 \%$ and $11 \%$ respectively. Solman and Feld note that these scores were considerably higher than those of other professions where only $16 \%$ of those surveyed had scores that placed then in the "high" disturbance category. These findings "are 
disturbing because they suggest that teachers are more likely than other professionals to need the intervention of a trained expert." Solman and Feld could, "only conclude that there are aspects of the teaching profession which contribute uniquely to these poor levels of general well-being" (p. 65).

Pierce and Molloy (1990) explored the relationship between school type, occupational stress, role perceptions and social support in teachers in Victoria, Australia. Their study included three affluent non-Catholic independent schools. Teachers in the independent schools had lower stress ratings on each of 13 variables. When asked the single greatest source of stress, these teachers identified "Teaching work load and time pressure (45.4\%), "Student problems, demands, and behavior" (18.4\%), and "Conflict between teaching and personal life" $(8.5 \%)$. Comparatively, the teachers working in public schools reported higher levels of role conflict and role ambiguity (as measured by the Role Questionnaire) which reflected the same patterns found in stress levels. Private school teachers also indicated higher levels of social support.

Closer to home, in this country Independent School Management, a private consulting firm which specializes in working with private schools has conducted research but it has not been published in professional journals. Sutton and Huberty (1984) compared the sources of stress and coping measures of private and public school teachers. While they found no significant differences their study employed a small sample and the teachers from the private school worked exclusively with the severely handicapped while the public school teachers taught regular students. Virtue (1992) conducted a study of teacher turnover in Christian schools. Of the teachers he surveyed $61.5 \%$ indicated that they felt that stress/burnout was a cause for teacher turnover. Virtue's study did not, however, examine the sources of stress and none of the respondents in his 
survey stated that stress constituted the reason they had left their previous position. Interestingly, fewer administrators in his study (39.8\%) suggested that stress/burnout contributed to teacher turnover in Christian schools.

Klanderman (1985) studied the sources of stress among teachers and principals employed in denominational schools in a large urban area. Teachers and principals working in member schools of the Lutheran Schools Association of Metropolitan New York participated in her research. The schools tended to be small ranging in population from 85 to 290 . One high school with 400 students also made up the research population. Klanderman conducted her research using the Teaching Events Stress Inventory. School violence emerged as a major source of concern among teachers even though there was no known history of violence in the schools. Respondents also indicated "Involuntary transfer to another school" generated considerable stress even though such transfers were not a common practice. Klanderman concluded that the data reflect teacher concerns about safety and security.

In 1982 the Independent School Health Association sponsored a conference on stress in residential schools. Sessions explored the stress of teachers who served in private boarding schools. Dey (1982) suggested that faculty as residential schools experience the "stress of ambiguity." Some examples Dey offered included the need to counsel and befriend students and to confront and at times "bust them" as well. Boarding school faculty are expected to be flexible, to maintain an open door policy, and to protect their own privacy as well. Dey also noted residential faculty "search in vain for professional dignity amidst late night emergencies, movie duty, nocturnal raids, room checks, attendance lists, and those periodic bouts with an overtired individual's momentary distemper--student, teacher, or administrator" (p. 48). At the same 
conference Cohen (1982) argued that the physical environments of boarding schools such as the lack of space can contribute to stress. In addition, he noted that these teachers are expected to be all things to all people including surrogate parent, coach, counselor, chauffeur, and travel agent.

Collectively, the extant research reveals that teaching can be a highly stressful occupation. Moreover, there are a multitude of sources for this stress which can be measured. A burgeoning literature indicates that the occupational stress of educators is a serious matter. Despite this concern, to date very little attention has been focused on teacher stress in private schools.

\section{Literature Related to the Research Questions}

Question \#1: What levels of stress do private school teachers experience in terms of student discipline and motivation?

Student discipline and motivation have been cited by several studies as a significant source of stress for public school teachers (Cichon \& Koff, 1980; Feitler \& Tokar, 1980; Morris \& Morris, 1980; Abernathy, Manera, \& Wright, 1985; Blase, 1986; Young, 1989; Okebukola \& Jegede, 1992). The few studies that exist on private school stress indicate that student discipline is stressful, but not to the extent that it is in public schools. The exception may be residential schools which Dey (1980) and Cohen (1980) have discussed as particularly stressful. In addition, there is evidence to suggest that private schools present fewer problems, and consequently less stress, in terms of student motivation and discipline. It is generally believed that because private schools are selective and reserve the right to have students withdraw who present themselves as discipline problems that there are few opportunities for problems in these areas. Cedoline (1982), for example, writing about public school administrator stress argued that 
the administration of private schools is less stressful because of few discipline problems and "an insidious selection process," that, "allows them to choose the students (or parents) they will accept" (p. 79). Solman and Feld's research with Catholic school teachers revealed that stress arising from discipline problems was very present but substantially lower than what their public school colleagues reported. While some private school do have an open admissions policy, many require admissions testing and admit only those student who can be successful in a rigorous academic setting. As a result, teachers in private schools should probably expect higher levels of student motivation and fewer discipline problems.

Question \#2: What levels of on-the-job stress do private school teachers experience in terms of personal distress, i.e. promotion opportunities. inadequate salary, status and respect, and recognition?

Teaching as a profession does not receive the respect that it once did. Phillips (1982), writing on stress in the major professions, has observed that while all of the professions are increasingly coming under closer scrutiny and criticism "the teaching profession has had to live in a glass house for decades" (p. 183). In framing the conditions of stress in teaching Esteve (1989) points to several factors related to status, respect, and recognition which serve as secondary and environmental contributors to teacher stress. Moreover, these factors are not specific to public school teachers, rather they apply to educators in both the public and private sectors. Among the forces at work that Esteve notes are: confusion over the goals of education, increasing contradictions in the role of the teacher, and changes in society's attitude towards the teacher. Esteve points out that teachers receive all of the blame for problems in education and little of the credit for what good occurs. This observation is validated by the 
work of Kaplan's (1992) study on the image of education in the mass media which is generally critical. Esteve also points out that teachers, not long ago where highly thought of as educated people and members of society. Their knowledge, self-sacrifice and vocation were esteemed. But now, our society tends to base social status on income, and the ideas of knowledge, self-sacrifice and vocation have lost their value as far society is concerned. For many parents the fact that someone has chosen to be a teacher is not indicative of a vocation but merely an 'alibi' for their having been unable to do 'anything better'; that is to say, to do something else which would make more money (p. 12-13).

This condition may be exacerbated by the fact that a large percentage of students attending private schools are from affluent families.

Contributing to the "personal distress" of teachers is also inadequate salaries for the work they do (Goodhall \& Brown, 1980; Needle, Griffin, \& Svendsen, 1981; Turk, Meeks, \& Turk, 1882; Kyriacou, 1987). This situation may be further exacerbated in private schools where historically salaries and benefits have been lower than in public schools. The salary differential, for example between a starting teacher with an undergraduate degree in Dade County Public Schools and a teacher in one of the county's large private school is several thousand dollars. This difference is even greater for smaller schools, particularly those that carry a religious affiliation. Given this salary differential, one might expect to find salary a particularly powerful stressor among private school teachers.

Question \#3: What are the stress levels of private school teachers based on professional investment, i.e. classroom autonomy, opportunities to air personal 
opinions, opportunities for professional growth, intellectual/emotional stimulation.

In his study of educational attitudes of private school teachers, however, Cookson (1980) asked private school administrators and teachers to rank the most important qualities and goals that headmasters and teachers should have. Their responses ranked knowledge and ability, dedication, kindness, high morality, and intellectual independence as those qualities. Another finding which emerged in Cookson's study was the professional autonomy that is valued by teachers and administrators alike.

Private school teachers expect to have autonomy in the classroom and Cookson's research suggests that administrators support that autonomy. This should serve to alleviate private school stress. Gupta (1981) has noted that teacher autonomy allows teachers to resolve conflicts or ambiguities thus reducing stress. Similarly, intellectual independence (and perhaps by association intellectual stimulation) are also highly valued. Another finding of note from the Cookson study relates to "professional investment." One of the four items on the TS/ used to measure stress on the factor is "My personal opinions are not sufficiently aired." One of the factors Cookson measured was professional autonomy in which teachers and headmasters were asked to rank a series of eight statements. Both teachers and headmasters ranked the following statement number one: "Teachers should be free to speak publicly on important social issues." Teachers and administrators ranked "Teachers should be very careful about expressing their personal opinions in the classroom," eighth and sixth respectively. 
Question \#4: What are the stress levels experienced by private school teachers in terms of work-related stress. i.e. lack of time for preparation, pace of the school day, shortchanging of personal priorities in light of time demands?

Predictors of work related stress in the literature include role overload time pressures, and large classes (Manera \& Wright, 1980; Gupta, 1981; Needle, Griffin, \& Svendsen, 1981; Blase, 1986; Okebukola \& Jegede, 1992). And while the research on private school teachers is scant one of the strongest similarities to emerge between private and public school teachers is the role they attribute to time pressures in terms of stress. In Solman and Feld's (1989) comparative study both Catholic and public school teachers listed time demands as their greatest stressor and in high percentages as well. In the case of Pierce and Molloy (1990) private school teachers considered teaching workload and time pressures as the single greatest source of stress in substantially greater numbers than public school teachers.

Private school teachers frequently have additional duties and time demands that their public school colleagues either do not have or for which they are compensated. Break and lunch duty, mandatory tutorial sessions before or after the regular school day begins or ends are typical expectations in private schools. The process of reporting student progress can be more intensive. Teachers routinely write individual progress reports on students at regular intervals. Generally, one finds fewer teacher work days in the calendars of private schools. The additional responsibilities of private school teachers are no doubt mitigated by the fact that they have smaller class sizes and fewer students. However, a reduction in student numbers translates into higher expectations both in terms of more individualized instruction and work assigned to students. For example, the language arts teacher who has only 80 students is 
expected to provide students with multiple writing experiences that are to be evaluated/graded with significant feedback. How are all of these factors reflected in the amount of work-related stress in private school teachers. 


\section{CHAPTER 3}

\section{Method}

This chapter presents the methodology for the study beginning with a description of the subjects who participated. The research design is explained followed by overview of the instrument selection. The overview provides a brief history of the development of the TSI, its basic components, as well as measures for reliability and validity. The chapter concludes with a documentation of the procedures followed in carrying out the study.

\section{Subjects}

This study was conducted with 316 teachers from private schools across the country. Schools which participated in the study consisted of seven institutions from six different states representing various types of private schools. Variables included the size of school and boarding/day. The schools selected did not include religiously affiliated institutions because these schools often operate within a larger organizational framework and represent a special kind of school culture as reflected in the work of Klanderman (1985) in which she examined teacher stress in Lutheran schools. Denominational schools are frequently an extension of a community of worship, e.g., parish, church, synagogue, and as such may present unique stressors for teachers.

Participating schools were selected from a list of schools supplied by two school heads familiar with the private school community. Criteria for selection consisted of demonstrated leadership, i.e., strong school head, sound financial condition, and sustained enrollment. In terms of a private school these are three characteristics of a nondistressed healthy institution. To help insure these criteria were met all schools asked to participate were currently members of the National Association of Independent Schools (NAIS). Membership in the NAIS 
requires a school to be in continuous operation for five years or more, have sound financial practices, and responsible governance and administration. Of the 13 schools asked to participate five declined or disqualified themselves because of recent changes in leadership or temporary stressful conditions at the school such as preparing for reaccreditation. A general description of those schools agreeing to participate follows:

School A is located in Charleston, South Carolina. It is a coeducational day school with grades $1-8$, a student population of 180 and a faculty of 16 teachers.

School B has a student population of approximately 350 students in grades preschool through seventh grade. The school is coeducational and located in Miami, Florida with a faculty of 40 teachers.

School C is a coeducational boarding/day school located in Hightstown, New Jersey. Approximately 490 students attend and the faculty numbers 55 . The school includes grades 8-12 and offers a postgraduate program as well.

School $D$ is located in a suburb area of Baltimore, Maryland. It is a day school offering a coeducational program for grades 6-12. The student enrollment is 500 students and the faculty number 55 .

School $E$ is a coeducational day school for preschool through grade 12 and is located in Cincinnati, Ohio. The school has a faculty of just over 100 teachers and a student enrollment of approximately 850 students.

School $F$ is located in Florida's capital. It offers a program beginning with the preschool and going up to grade 12. A coeducational day school, the school has a faculty of approximately 80 teachers and an enrollment of almost 950 students. 
School $\mathrm{G}$ is a coeducational day school in Charlotte, North Carolina. Over 1,130 students are enrolled in grades PS-12 and the faculty numbers 104 .

The sample population from these seven schools represented full time teachers at the elementary, middle, and high school levels who were regular classroom teachers. Approximately one third of the subjects were elementary teachers and another third taught at the secondary level. Middle school teachers made up 17.7 percent of the sample population and nearly 10 percent of the subjects taught at more than one level (see Table 1). The sample did not include teachers whose primary responsibilities were administrative. Nearly half of the teacher reported having advanced degrees (see Table 2).

\section{Table 1}

\section{Grade Levels Taught by Teachers}

Level

$\underline{\mathrm{n}}$

percent

Elementary

Middle

Secondary

More than one level

Unreported
119

56

104

30
33.7

17.7

32.9

9.5

2.2

The majority of the sample population were females. Only $25.6 \%$ of the teachers were males (see Table 3). The median age of the sample was 42 and the median years of teaching 13. Teachers ranged in experience from the first year to 36 years in the classroom. 
Table 2

Educational Level of Attainment

Degree n $\quad$ percent

$\begin{array}{lcc}\text { Associate } & 2 & .6 \\ \text { Bachelors } & 153 & 48.4 \\ \text { Masters } & 133 & 42.1 \\ \text { Doctorate } & 10 & 3.2 \\ \text { Unreported } & 18 & 5.7\end{array}$

Table 3

Gender of Sample Population

n $\quad$ percent

male

female

unreported
81

221

14
25.6

69.9

4.4

\section{Research Design}

This study is designed to develop a profile of occupational stress in teachers in private schools. In developing such a profile the research design seeks to answer the question; "What does stress look like in private schools?" This study is, therefore, descriptive. There are, however, additional components of the study arising from some exploratory questions addressed in the research. Once a stress profile was assembled based on the data from the 
TSI this profile was compared to the results of Fimian's (1988) research employing a large public school teacher population which he used to norm the TSI. This comparison was only exploratory, however, because the data in Fimian's work was collected between 1980-1987. More recent data using the TS/ was not currently available.

This study also includes teachers from a variety of different schools as highlighted in the above section on subjects. Exploratory comparisons were made between teacher populations based on these variables, i.e., size of school, boarding/day. Although teachers represented both elementary, middle, and high school grade levels this was not examined as a variable. Fimian (1983) found no significant relationship between the grade level at which one teaches and the stress level expereinced while teaching. Because there was no manipulation of subjects or data these portions of the research can be described as causal comparative exploratory questions.

\section{Instrument Selection}

Data collection for assessing the occupational stress levels in private school teachers was conducted using the Teacher Stress Inventory (TSI) developed by Fimian (1988) (Appendix A). Teacher stress has been measured a number of different ways with a self-report format proving the most useful (Kyriacou, 1987). The TSI, which uses a self-report format, is designed to be used to: conduct research on teacher stress, allow teachers to assess their own stress levels, and as a survey instrument to assess the amount of stress within an educational system.

The instrument is a 49-item, ten factor self-report measure that relays the levels of occupational stress in public school teachers. The first five factors of the TS/ are concerned with causes of stress: time management, work-related 
stressors, professional distress, discipline and motivation (among students), and professional investment, e.g., participation in decision making. The inventory also contains five factors which assess stress manifestations: emotional, fatigue, cardiovascular, gastronomical, and behavioral. A separate mean score for each of the items is derived by averaging the ratings for the items that make up each of the 10 factors. By adding the average scores of each of the ten factors a total score is obtained. Collectively, the ten factors represent the stress construct termed "Total Stress." The mean scores for the subscales and the total scale fall within three ranges: significantly high, average and significantly low levels of stress. Within the average range scores falling either above or below the mean can be said to be higher or lower than average.

Fimian developed the TSI over a period of several years. The initial version of the TSI was a pilot instrument. Establishing face validity, he surveyed the literature and located 135 sources and manifestations of teacher stress. Fimian organized these sources and manifestations into one or more of 13 categories. Elimination of redundant and conceptually similar items resulted in a list of 79 items. Subsequently, Fimian pared this list of items down to 63 usable items based upon feedback from 14 graduate students and two professors from a college of education and 16 teachers. These 63 items became the pilot version of the TS/ termed the Teacher Stress Scale. Two Likert-type scales accompanied each item to measure strength and frequency. He then distributed the pilot stress scale to 363 teachers. Following a statistical analysis of the responses 30 of the 63 items were retained. These 30 items became the core of a second version of the TSI. An additional twelve items were added to the inventory, bringing the total items number to 42 . This amended version of the inventory employing the same two Likert scales measuring frequency and 
strength was again distributed to teachers during the 1980-81 school year.

Again, factor and reliability analyses were conducted resulting in the deletion of one item. Fimian found the factor patterns and alpha reliability estimates were nearly identical to those found in the earlier study.

In developing content reliability Fimian assembled a group of "experts " on teacher stress and burnout (Fimian, 1987). Expertise was established by having conducted research, published a book, monograph or article, or conducted stress management workshops on teacher stress and burnout. Five samples of experts taken from an address list of experts developed from the literature each academic year provided data once each in one of five summers using a modified version of the TSI. This process of collecting content appraisal feedback resulted in various modifications of the $T S /$ including the addition of a section on "Personal and Professional Information" and a reorganization of several conceptually related items resulting in an eight item factor entitled "Time Management."

Fimian established convergent validity in three ways. He correlated TSI scores with ratings made independently by a person who knew the teacher well. $T S /$ scores were also correlated with the presence of personal and professional characteristics selected hypothetically to correlate very little with TSI scores, e.g., sex, age, experience. Finally, Fimian correlated TSI scores with measures of various psychological, physiological, and organizational constructs hypothesized to be related to stress, e.g., Maslach Burnout Inventory, Collectively, these three sets of correlations evidenced convergent validity of the instrument.

Fimain measured internal consistency reliability estimates for both the total score as well as subscales using Cronbach's coefficient alpha. Alpha 
reliability for the total scale measured .93 . Reliability estimates for subscales ranged from a low of .75 to a high of .88 .

Generally, the TS/ received favorable reviews in the Mental Measurements Yearbook. Reviewers found acceptable levels of internal consistency reliability as well as content, convergent, factorial and construct validity. One reviewer noted the test-retest reliability was limited by sample size and the length of time between administrations. Weaknesses were noted regarding the norm group which consisted of 3,401 public school teachers of which the majority were special education teachers $(n=2,352)$. In addition, $87 \%$ of teachers in the norm population had advanced degrees.

\section{Procedures}

In the spring of 1996 Dr. Michael Fimian, a leading expert on teacher stress and the author of the TS/ was contacted to discuss the possibility of using his instrument to measure the occupational stress of teachers in private schools. His comments were both favorable and encouraging. While developed for public school teachers, he noted that the items on the TS/ should serve as effective measures for private school teachers because they represented stressors inherent to the profession.

During the summer contact was made with 13 private schools by phone. Efforts were made to try to include a variety of types of schools. School heads received an explanation of the research project and were asked if they would commit their faculties to participation. Criteria for selection of schools was 
explained to each headmaster/headmistress. Three schools declined to participate. In two other instances interested schools disqualified themselves because of developments taking place within the school which might have placed additional stress on the teachers, e.g., new leadership, participation in the reaccreditation process. Those school agreeing to participate received a confirmation letter (Appendix B), a copy of the TSI, and some background information on administration of the inventory. Individual teacher participation in the study was voluntary.

In September the heads of the eight schools were called to again verify their schools' participation in the study and to ascertain the number of full-time faculty. Later that month a cover letter (Appendix C) and an additional copy of the guidelines for administration were mailed to each school with the surveys. The heads of school were requested to administer the TSI some time during the month of October after the initial stress of the beginning of the school year had passed. In the case of one school, although the faculty numbered approximately 100 , only $18-20$ teachers agreed to participate, so only 20 surveys were mailed. For the other seven schools a survey was provided for each faculty member bringing the total to 457 surveys.

By mid-November seven of the eight schools had responded with 254 surveys $(55.6 \%)$ being received. One school, however, had not returned any surveys. Follow-up calls were made to the school which had not participated as 
well as two other schools. This resulted in the completion of eight more surveys. However, in a conversation with the headmaster of the school which had not returned any surveys, he indicated that his division heads expressed various degrees of reluctance at participating in the study. The general consensus among these administrators was that the wording of the TS/ was too negative. The project was reviewed with this headmaster and he acknowledged his willingness to have his school participate. He noted that he had encouraged his administrative team to administer the surveys but it expressed continued reluctance. With the head of school's permission each administrator was contacted by phone. The purpose of the research project was explained and their concerns were addressed. Each was provided with an explanation of the research design. It was explained to them that the focus of the project was not on individual responses, rather the development of a profile of teacher stress in private schools and as such individual responses would be folded into a much larger data pool which would further insure anonymity. Each administrator agreed to meet with his/her fellow administrators after we had spoken by phone. Collectively they agreed to participate and 65 of the 85 faculty $(76.5 \%)$ completed the TSI.

With the completion of the additional 73 surveys a total of $327(71.6 \%)$ were returned. Three of the 327 surveys proved unusable resulting in a 70.9 response rate. As noted above, at one school only 18-20 teachers agreed to fill 
out the survey, however, only eight teachers at this school with a faculty of approximately 100 completed the TSI. Because this represented a very low percentage of the faculty it was not considered a fair representation of the school's teacher population. As a result this school was dropped from the research population and the eight surveys were subtracted from the original. The percentage of usable surveys returned based on this adjusted research population was $72.3 \%$, i.e., 316 of 437 .

Table 4

Alpha Reliability for Subscales and Total Stress Factor

Subscale

Reliability

Stress sources

Time management .74

Work-related stressors .83

Professional distress .86

Discipline and motivation .83

Professional investment

Stress manifestations

Emotional manifestations

Fatigue manifestations .77

Cardiovascular manifestations Gastronomic manifestations

Behavioral manifestations

Total

Total Factor

.92

Alpha reliabilities were computed for individual factor and the total stress factor and generally yielded good results (see Table 4). The reliability for the 
total stress factor is .92 . Reliability for the Stress Sources factors range from .86 to .74 . For Stress Manifestations the range is from .41 to .81 . All of the reliability scores are in the acceptable range with the exception of Behavioral Manifestations. The reliability estimate for this factor is .41 . 


\section{CHAPTER 4}

Data Analysis

In order to develop a stress profile for private school teachers a set of descriptive statistics providing the mean and standard deviation for each of the ten factors as well as the 49 individual items was generated. The mean of the ten factors making up the TS/ provided an overall rating of the stress level of the private school teacher.

\section{Stress Ratings by Factor: Stress Sources}

The stress strength for a particular factor as well as total stress strength is determined by comparing the mean score against high-low cutoff points in the TS/ manual. Three ranges are provided. Stress strength may be said to be "significantly high," "average," or "significantly low" depending on what range in which the factor mean score falls. Within the midrange scores usually vary somewhat. The average range extends one $\mathrm{SD}$ above and below the mean of the group $(n=3,401)$ used to norm the TSI. Scores falling one SD above or below the factor mean score can be said to be higher or lower than average, but not significantly higher or lower than average. For example, the factor Discipline and Motivation in this study has a mean of 2.12. In the manual the mean for this factor is 3.00 . A score of 4.00 or higher would indicate a significantly high level of stress. Any score falling between 3.00 and 4.00 would indicate a higher than average level of stress, but not significantly higher. Conversely, the cut-off point for a significantly low level of stress for this factor is 1.90 . Therefore, any mean 
falling between 1.90 and 3.00 would indicate a lower than average, but not significantly lower than average stress level. With a mean of 2.12 , private school teachers evidence a stress level which falls in the midrange and can be described as lower than average, but not significantly so. In addition, because the means vary from factor to factor simple comparisons between factors based solely on means are not possible. A mean score of 2.12 , for example, on the Time Management factor would place the stress strength in the significantly low range, while the same score for Professional Distress falls within the midrange.

Levels of stress for factors of stress sources ranged from a high $(M=3.32)$ to a low $(M=1.97)$ (see Table 5). Measures for the factor, Time Management, are related to issues of overcommitment, trying to do more than one thing at a time, and feeling like there is not enough time to get things done. Although Time Management received the highest mean rating $(M=3.32)$ of all of the factors this mean fell within in the average range for level of stress.

Work-Related stressors such as amount of work, caseload, and class sizes have a mean of 3.04 indicating lower than average stress. The third highest mean came from Professional Distress which received a total rating of 2.62 placing this stressor in the lower than average range as well. Also within the lower than average range is Professional Investment $(M=1.97)$. Items making up this factor included the opportunity to air one's opinions, decision making authority, and opportunities for professional growth. Discipline and Motivation related to students $(M=2.12)$ has the lowest stress strength among Stress 
Sources with private school teachers indicating that these factors served as only

a mild source of stress.

Table 5

Means and Standard Deviations for Stress Sources and Manifestations and Total Stress Strength for Private Schools

Factors

$\underline{M}$

SD

\begin{tabular}{|c|c|c|}
\hline \multicolumn{3}{|c|}{ Stress sources } \\
\hline Time management & 3.32 & .68 \\
\hline Work-related stressors & 3.04 & .86 \\
\hline Professional distress & 2.62 & 1.06 \\
\hline Discipline and motivations & 2.12 & .83 \\
\hline Professional investment & 1.97 & .81 \\
\hline \multicolumn{3}{|c|}{ Stress manifestations } \\
\hline Emotional manifestations & 2.46 & .95 \\
\hline Fatigue manifestations & 2.40 & .85 \\
\hline Cardiovascular manifestations & 1.91 & 1.07 \\
\hline Gastronomic manifestations & 1.60 & .96 \\
\hline Behavioral manifestations & 1.27 & .44 \\
\hline \multicolumn{3}{|c|}{ Total stress strength } \\
\hline Total stress & 2.27 & .53 \\
\hline
\end{tabular}

Note. The higher the mean, the greater the stress level. The mean score range is 1 to 5 .

\section{Stress Ratings by Factor: Stress Manifestations}

The means for the factors for Stress Manifestations were generally lower than those of Stress Sources (see Table 5). No stress manifestation received a mean of 3.00 or higher. Two of the factors, Emotional $(M=2.46)$ and Fatigue $(M=.2 .40)$ Manifestations have means indicating average stress levels. Emotional Manifestations revolve around feelings of insecurity, vulnerability, inability to cope, depression and anxiety. Physical exhaustion and weakness, procrastination, and sleeping more than usual provided measures of fatigue. Cardiovascular and Gastronomic Manifestations with means of 1.91 and 1.60 
respectively are the only factors which garnered slightly higher than average stress levels. The Behavioral Manifestation factor, with a mean rating of 1.27 , includes such items as the use of over-the-counter and prescription drugs, alcohol and absenteeism. A mean of 1.27 indicates an average stress level. Fimian notes, however, that these behavioral responses to stress tend to be underreported. In addition the alpha reliability estimate for this subscale is .41 . Composite Score for Factors

An overall stress rating using the $T S I$ is calculated by adding the means for the five stress sources and five stress manifestation factors and dividing by ten. This mean calculated by using the 10 factors provides a score for the construct termed "stress." The total stress mean is 2.27 . The high and low cutoff points for the average range for the total scale are 2.00 to 3.25 with a mean of 3.00 indicating an average level of stress. The mean score of private school teachers at 2.27 indicates that occupational stress for these teachers is fairly mild falling in the lower than average range.

\section{Analysis of Question \#1}

The first question focuses on what are the levels of stress that private school teachers exhibit based on student discipline and motivation. A mean score of 2.12 on this subscale indicates that private school teachers experience lower, but not significantly lower than average levels of stress in terms of these issues. None of the six items making up this source of stress factor have a mean approaching 3.00 , i.e., medium strength. The mean scores of the items 
making up this source of stress factor range from 1.75 to 2.69 . Teachers indicated that the greatest source of stress is students whom teachers felt could do better if they tried. Least stressful are inadequately or poorly defined discipline problems.

\section{Analysis of Question \#2}

The second question explores the stress levels that private school teachers experience in terms of professional distress. With a mean of 2.62 on this factor the mean score is well within the lower than average range. Of the five items making up this factor, only one received a mean rating of medium to great strength, i.e., receiving an inadequate salary. The mean score of this item was 3.26. All of the other items fell within a range of 2.01 and 2.84 (see Table 10). The one item approaching a rating of medium strength was the lack of recognition for the extra work and/or good teaching that teachers felt they $\operatorname{did}(M=2.84)$.

\section{Question \#3}

What are the levels of stress that private school teachers experience based on professional investment? The answer to this questions revolves around four items: "My personal opinions are not sufficiently aired," "I lack control over decisions made about classroom/school matters," "I am not emotionally/intellectually stimulated on the job," and "I lack opportunities for professional improvement." The mean for this factor is 1.97 (see Table 5). A score falling between 1.50 and 2.80 places the level of stress within the lower 
than average, but not significantly low range. Two of the items in the factor received mean ratings of over 2.00 ("mild strength" or "barely noticeable"). The item on airing personal opinions had a mean of 2.13 and control over decisions a mean of 2.20 . The factor items on emotional/intellectual stimulation and opportunities for professional growth had means of 1.58 and 1.66 respectively. These are both relatively low means.

\section{Question \#4}

The final question revolves around the levels of stress that private school teachers experience in terms of work-related stress. While the work related stress factor is the second highest of the ten factors with a mean score of 3.04 , it is clearly not indicative of a high amount of work related stress for teachers. The two highest mean ratings on individual items of this factor were 3.55 for the items "There is too much work to do" and 3.50 for the item, "My personal priorities are being shortchanged due to time demands." Only these two items begin to approach a strength level that might be considered indicative of high stress. The remaining four items fell close to or below the 3.00 (medium strength) level.

\section{The Stress Profile of Private School Teachers}

With the dearth of research on occupational stress in private school teachers the main goal of this study was the development a stress profile of those professionals who work in education's private sector. With a population sample of 316 teachers from a variety of different schools one can begin to 
develop a composite of what stress "looks like" in the private school. Generally, private schools do not represent particularly stressful environments. As noted above, the total stress score for the sample population measured 2.27 with a standard deviation of .53 (see Table 5). Because it is below the average mean of 2.50 this total stress score indicates private school teachers experience lower than average, but not significantly low levels of occupational stress.

\section{Profile: Factor Data}

Data analysis by Stress Sources and Manifestations factors as well as individual items help flesh out this profile. All of the Stress Sources factors, with the exception of Time Management, register means that fall in the lower than average, but not significantly low range. Time Management has a mean of 3.32 which is very close to the 3.25 average mean. Private school teachers, therefore, may feel that time management, e.g., not enough time to get things done, little time to relax, overcommitment, contributes to their levels of stress, however, this contribution can be described as moderate at best. With a mean of 1.97 the Discipline and Motivation factor comes the closest to approaching a low level of stress for both the Stress Source and Manifestation factor.

The stress levels associated with the Stress Manifestation factor are slightly higher than those for the Stress Sources factor. Emotional Manifestations and Fatigue Manifestations, with means of 2.46 and 2.40 , are very near the average mean and point to moderate levels of stress. The former, with a mean of 2.46 , points to some feelings of insecurity, anxiety and feelings of 
vulnerability among private school teachers, but it is fairly mild. Likewise the latter factor indicates that some of the fatigue associated with teaching in private schools is stress related, however, with a mean of 2.40 it is fairly mild as well. The Cardiovascular and Gastronomic Manifestation factors have means that are higher than average, but not significantly higher. Like the factors related to emotional and fatigue issues, stress manifestations arising from these two areas contribute to private school teacher stress, but still only moderately.

The Behavioral Manifestations factor, with a mean of 1.27 is just slightly below the average mean. Some caution, however, should be used in interpreting these results. Again, as Fimain (1988) has noted, behaviors related to this factor such as use of alcohol, prescription and over-the-counter drugs and calling in sick tend to be underreported. In addition, the alpha reliability for this factor is .41 the lowest of all of the reliability estimates for all of the factors.

\section{Profile: Individual Item Data}

An analysis of the rank order of items by strength helps provides a complete understanding of private school teachers' stressors. As would be expected, most of the top 10 items came from the factors on Time Management and Work-Related Stressors which contain the largest means in terms of the ten factors (see Table 6). "There isn't enough time to get things done," constitutes the only item with a mean exceeding 4.00 (great strength). This item has a mean of 4.10. A related item, "I have little time to relax/enjoy the time of day" has a mean rank close to 4.00 with 3.88 indicating a significant source of stress. 
Two other highly ranked items of interest which are not part of the factors on Time Management and Work-Related Stressors relate to salary and anxiety. "I receive an inadequate salary for the work I do" has a mean of 3.26 and ranked seventh among the 49 items of the TSI. Only one stress manifestation ranks among the ten strongest items, "I respond to stress by feeling anxious." The mean for this manifestation is 3.05 indicating medium strength. Rounding out the number of items with a mean rank of 3.00 and above is eleventh ranked, "School day pace is too fast."

Nearly half of the 49 items generated means between 2.00 and 3.00 . Of the 24 items with means falling between mild and medium strength, i.e., 2.00 and $3.00,15$ came from the Stress Source factors and 9 from the items on Stress Manifestations. Several of the items are of particular interest and warrant comment.

Table 6

Rank Order of Individual Items by Stress Strength

\begin{tabular}{llccc}
$\begin{array}{l}\text { Rank } \\
\text { order }\end{array}$ & Abbreviated item stem & Item & M & SD \\
\hline 1 & Not enough time to get things done & 7 & 4.10 & .99 \\
2 & Have little time to relax & 4 & 3.88 & 1.10 \\
3 & Feel uncomfortable wasting time & 6 & 3.68 & 1.20 \\
4 & Too much work to do & 10 & 3.55 & 1.10 \\
5 & Personal priorities are being shortchanged & 13 & 3.50 & 1.21 \\
6 & Easily overcommit myself & 1 & 3.41 & 1.03 \\
7 & Receive an inadequate salary & 18 & 3.26 & 1.40 \\
8 & Feeling anxious & 34 & 3.22 & 1.27 \\
9 & Little time to prepare & 9 & 3.17 & 1.08 \\
10 & Do more than one thing at a time & 3 & 3.05 & 1.37 \\
11 & School day pace is too fast & 11 & 3.04 & 1.19 \\
12 & Physical exhaustion & 38 & 2.95 & 1.35 \\
13 & Become impatient & 2 & 2.93 & 1.04 \\
14 & Lack recognition & 19 & 2.84 & 1.39 \\
15 & Think about unrelated matters & 5 & 2.80 & 1.17
\end{tabular}




$\begin{array}{lllll}16 & \text { Rush in my speech } & 8 & 2.72 & 1.27 \\ 17 & \text { Students who would do better if they tried harder } & 22 & 2.69 & 1.13 \\ 18 & \text { Becoming fatigued in short time } & 37 & 2.66 & 1.30 \\ 19 & \text { Lack promotion/advancement opportunities } & 15 & 2.53 & 1.38 \\ 20 & \text { Too much administrative paperwork } & 14 & 2.51 & 1.22 \\ 21 & \text { Caseload/class too big } & 12 & 2.47 & 1.24 \\ 22 & \text { Need more status and respect } & 17 & 2.40 & 1.32 \\ 23 & \text { Feeling depressed } & 33 & 2.35 & 1.27 \\ 24 & \text { Procrastinating } & 36 & 2.34 & 1.26 \\ 25 & \text { Teaching students who are poorly motivated } & 23 & 2.29 & 1.10 \\ 26 & \text { Unable to cope } & 32 & 2.27 & 1.23 \\ 27 & \text { Feeling insecure } & 30 & 2.23 & 1.24 \\ 28 & \text { Feeling vulnerable } & 31 & 2.21 & 1.21 \\ 29 & \text { Lack control over decisions } & 27 & 2.20 & 1.22 \\ 30 & \text { Personal opinions not sufficiently aired } & 26 & 2.13 & 1.15 \\ 31 & \text { Feelings of heart pounding or racing } & 41 & 2.08 & 1.30 \\ 32 & \text { Physical weakness } & 39 & 2.07 & 1.20 \\ 33 & \text { Authority rejected by pupils/administration } & 25 & 2.05 & 1.25 \\ 34 & \text { Having to monitor pupil behavior } & 21 & 2.05 & 1.12 \\ 35 & \text { Not progressing rapidly in job } & 16 & 2.05 & 1.12 \\ 36 & \text { Sleeping more than usual } & 35 & 1.96 & 1.19 \\ 37 & \text { Discipline problems in the classroom } & 20 & 1.19 & 1.04 \\ 38 & \text { Feelings of increased blood pressure } & 40 & 1.88 & 1.31 \\ 39 & \text { Rapid/shallow breath } & 42 & 1.77 & 1.17 \\ 40 & \text { Stomach acid } & 45 & 1.76 & 1.30 \\ 41 & \text { Inadequate/poorly defined discipline policies } & 24 & 1.75 & .96 \\ 42 & \text { Lack opportunities for improvement } & 29 & 1.66 & .97 \\ 43 & \text { Not emotionally/intellectually stimulated } & 28 & 1.58 & .86 \\ 44 & \text { Stomach cramps } & 44 & 1.54 & 1.08 \\ 45 & \text { Stomach pain of extended duration } & 43 & 1.51 & 1.05 \\ 46 & \text { Using over-the-counter drugs } & 46 & 1.43 & .98 \\ 47 & \text { Using alcohol } & 48 & 1.33 & .70 \\ 48 & \text { Using alcohol } & 47 & 1.22 & .77 \\ 49 & \text { Calling in sick } & 49 & 1.09 & .45\end{array}$

Note. The higher the mean, the greater the stress level. The mean score range is 1 to 5 .

\section{Comparative Analysis of Private Schools by Type and Size}

Having developed a stress profile of private schools, a secondary point of interest is to explore possible differences between stress levels based on the variables of school type, i.e., boarding and day schools and size. 
Boarding and Day Schools.

Dey's (1882) and Cohen's (1982) contention that boarding school teachers are more stressed in their professional lives is not supported by this study. A comparative analysis of the stress of boarding and nonboarding school teachers does not reveal significant differences in stress levels. Although boarding school faculty report higher levels of stress on each of the ten factors, the stress level is significantly greater stress on only one of the factors, i.e., Time Management. The mean for boarding school faculty is 3.32 and for day school teachers 2.88 , significant at the $p<.05$ level. On the combined factors the mean difference between total stress scales is only .12 (see Table 7). 
Table 7

Comparison of Boarding and Nonboarding Private Schools on Factors for Stress Sources and Manifestations and Total Stress

\begin{tabular}{|c|c|c|c|c|c|c|}
\hline \multirow[t]{2}{*}{ Factor } & \multicolumn{2}{|c|}{$\begin{array}{l}\text { boarding } \\
(\underline{n}=30)\end{array}$} & \multicolumn{2}{|c|}{$\begin{array}{l}\text { nonboarding } \\
(\underline{n}=286)\end{array}$} & \multirow[t]{2}{*}{ 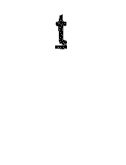 } & \multirow[t]{2}{*}{ p-value } \\
\hline & $\underline{M}$ & $\underline{\mathrm{SD}}$ & $\underline{M}$ & $\underline{\mathrm{SD}}$ & & \\
\hline \multicolumn{7}{|c|}{ Stress sources } \\
\hline Time management & 3.32 & .65 & 2.88 & .67 & 2.61 & $.011^{*}$ \\
\hline Work-related stressors & 3.32 & .89 & 2.72 & .74 & 1.62 & .110 \\
\hline Professional distress & 3.06 & 1.16 & 2.34 & .96 & -.89 & .377 \\
\hline Discipline and Motivation & 2.09 & .73 & 1.96 & .65 & -1.23 & .233 \\
\hline Professional investment & 1.74 & .82 & 1.57 & .65 & .94 & .349 \\
\hline \multicolumn{7}{|c|}{ Stress manifestations } \\
\hline $\begin{array}{l}\text { Emotional } \\
\text { manifestations }\end{array}$ & 2.30 & .67 & 2.07 & .80 & 1.21 & .231 \\
\hline Fatigue manifestations & 2.30 & .74 & 2.19 & .71 & .47 & .644 \\
\hline $\begin{array}{l}\text { Cardiovascular } \\
\text { manifestations }\end{array}$ & 2.27 & .78 & 1.53 & .74 & .20 & .839 \\
\hline $\begin{array}{l}\text { Gastronomical } \\
\text { manifestations }\end{array}$ & 1.57 & .86 & 1.29 & .66 & 1.66 & .102 \\
\hline $\begin{array}{l}\text { Behavioral } \\
\text { manifestations }\end{array}$ & 1.60 & .26 & 1.19 & .36 & -.69 & .491 \\
\hline \multicolumn{7}{|c|}{ Total stress strength } \\
\hline Total stress & 2.09 & .41 & 1.97 & .39 & 1.15 & .254 \\
\hline
\end{tabular}

Note. The higher the mean, the greater the stress level. The mean score range is 1 to 5 .

${ }^{*} p<.05$

An Analysis of Schools by Size.

A MANOVA on the five stress source factors is significant, $F(10,616)=3.32, p<.001$ (see Table 8). Univariate one-way analyses of variance were carried out on each of the Stress Sources factors by size of school (small, medium, and large). The data analysis revealed significant differences on each 
of the factors. The stressor of Time Management is significant by school size, $F(2,312)=4.83, p=.009$. Tukey's test indicates that teachers in large schools average more strength $(M=3.39)$ than teachers in medium schools $(M=3.10)$. On the Work-Related factor the results are significant as well, $F(2,312)=5.98$, $p=.003$ with Tukey's test indicating that teachers in large schools average more strength $(M=3.15)$ than teachers in small schools $(M=2.71)$. The Professional . Distress factor was significant as well, $F(2,312)=11.55, p<.001$. Moreover, Tukey's post hoc test indicated that teachers in large schools averaged significantly greater stress strength $(M=2.82)$ than their colleagues in both small $(M=2.25)$ and medium schools $(M=2.21)$ on this factor. While the differences on the Discipline and Motivation and Professional Investment factor are significant based on school size, the differences are significant for medium and large size schools only. 
Table 8

Comparison of Schools by Size for Stress Sources and Manifestations and Total Stress Strength

\begin{tabular}{|c|c|c|c|c|c|c|c|c|}
\hline \multirow[t]{2}{*}{ Factor } & \multicolumn{2}{|c|}{$\begin{array}{c}\text { small } \\
(\underline{n}=43)\end{array}$} & \multicolumn{2}{|c|}{$\begin{array}{l}\text { medium } \\
(\underline{n}=61)\end{array}$} & \multicolumn{2}{|c|}{$\begin{array}{c}\text { large } \\
(\underline{n}=211)\end{array}$} & \multirow[t]{2}{*}{$\underline{E}$} & \multirow[t]{2}{*}{$\mathrm{p}$-value } \\
\hline & $\underline{M}$ & $\underline{\mathrm{SD}}$ & $\underline{M}$ & $\underline{\mathrm{SD}}$ & $\underline{M}$ & $\underline{\mathrm{SD}}$ & & \\
\hline \multicolumn{9}{|c|}{ Stress sources } \\
\hline Time management & 3.26 & .69 & 3.10 & .69 & 3.40 & .66 & 4.83 & $.009^{* *}$ \\
\hline $\begin{array}{l}\text { Work-related } \\
\text { stressors }\end{array}$ & 2.71 & .96 & 2.89 & .83 & 3.15 & .83 & 5.98 & $.003^{* *}$ \\
\hline $\begin{array}{l}\text { Professional } \\
\text { distress }\end{array}$ & 2.25 & .95 & 2.21 & 1.06 & 2.82 & 1.03 & 11.55 & $<.001^{* *}$ \\
\hline $\begin{array}{l}\text { Discipline and } \\
\text { motivation }\end{array}$ & 2.10 & .95 & 1.86 & .69 & 2.21 & .83 & 4.38 & $.013^{*}$ \\
\hline $\begin{array}{l}\text { Professional } \\
\text { investment }\end{array}$ & 1.70 & .75 & 1.66 & .73 & 2.01 & .83 & 5.93 & $.003^{* *}$ \\
\hline \multicolumn{9}{|c|}{ Stress manifestations } \\
\hline $\begin{array}{l}\text { Emotional } \\
\text { manifestations }\end{array}$ & 2.27 & .89 & 2.18 & .75 & 2.57 & .99 & 5.02 & $.007^{\star \star}$ \\
\hline $\begin{array}{l}\text { Fatigue } \\
\text { manifestations }\end{array}$ & 2.30 & .93 & 2.23 & .72 & 2.46 & .86 & 2.10 & .124 \\
\hline $\begin{array}{l}\text { Cardiovascular } \\
\text { manifestations }\end{array}$ & 1.82 & 1.06 & 1.52 & .74 & 2.01 & 1.10 & 5.37 & $.005^{* *}$ \\
\hline $\begin{array}{l}\text { Gastronomical } \\
\text { manifestations }\end{array}$ & 1.43 & .63 & 1.43 & .78 & 1.70 & 1.05 & 2.74 & .066 \\
\hline $\begin{array}{l}\text { Behavioral } \\
\text { manifestations }\end{array}$ & 1.18 & .28 & 1.16 & .31 & 1.32 & .49 & 4.08 & $.018^{*}$ \\
\hline \multicolumn{9}{|c|}{ Total stress strength } \\
\hline & 2.12 & .45 & 2.03 & .40 & 2.37 & .56 & 12.44 & $<.001^{* *}$ \\
\hline
\end{tabular}

Note. The higher the mean, the greater the stress level. The mean score range is 1 to 5 .

${ }^{*} p<.05,{ }^{* *} p<.001$

Therefore, one can see that while there are significant differences in stress levels on the variable of school size, these differences do not translate 
into a real difference in terms of the actual stress levels of teachers in these schools. While some of the factor scores for larger schools fall in the slightly higher than average range the total stress scores of teachers in all three size schools fall comfortably within the lower than average range.

The results of a MANOVA reveal an overall significant difference by school size is present within the factors making up the Stress Manifestations, . $F(10,610)=1.96, p<.05$. Similarly, as with the Stress Source factors an analysis using Tukey's post hoc test, was carried out on each of the Stress Manifestation factors. Only three of the five factors are significantly different. Moreover, in the case of each of these three factors, Emotional, Cardiovascular, and Behavioral Manifestations, the significant difference by size is between only . the large and medium size schools. No significant differences between the large and small schools emerge.

\section{Comparative Analysis of Private and Public Schools}

As noted previously, an exploratory question in this study is to examine the possible differences in stress levels between public and private school teachers. This analysis is possible using the profile of teacher stress developed above and the data used to norm the TS/ available in the TS/ manual.

\section{Comparison of TS/ Factors and Total Stress Strength}

Using a $t$-test for independent samples it was found that private and public schools differed significantly on four of the five factors comprising Stress Sources: Time Management, Professional Distress, Discipline and Motivation, 
and Professional Investment (see Table 9). All four of these factors registered significant differences at the $p<.01$ level. A finding of importance is that on only one of the factors, Time Management, do private school teachers have higher levels of stress than public school teachers. On the other factors private school teachers experience lower levels of stress than their colleagues in public schools.

Table 9

Comparison of Private and Public Schools on Total Stress and Factors for Stress Sources and Stress Manifestations

TSI scale and factors

\begin{tabular}{|c|c|}
\hline $\begin{array}{l}\text { private } \\
(\underline{n}=316)\end{array}$ & $\begin{array}{c}\text { public } \\
(n=3401)\end{array}$ \\
\hline$M \quad S D$ & $\underline{\mathrm{M}} \quad \mathrm{SD}$ \\
\hline
\end{tabular}

Total stress strength

$\begin{array}{lll}2.27 & 0.54 & 2.60\end{array}$ Stress sources

Time management Work-related stressors Professional distress Discipline and motivation Professional investment

Emotional manifestations Fatigue manifestations Cardiovascular manifestations Gastronomic manifestations Behavioral manifestations
$3.32 \quad 0.68$

$3.04 \quad 0.86$

2.62

1.06

2.13

0.83

1.90

0.81

3.20

3.10

3.10

2.90

2.70

Stress manifestations

$\begin{array}{lllll}2.46 & 0.95 & 2.60 & -2.61 & .009^{* *} \\ 2.40 & 0.85 & 2.50 & -2.05 & .042^{*} \\ 1.91 & 1.07 & 1.90 & 0.17 & .863 \\ 1.60 & 0.96 & 1.80 & -3.62 & <.001^{* *} \\ 1.27 & 0.44 & 1.50 & -9.31 & <.001^{* *}\end{array}$

$-11.04<.001^{* *}$

$3.16 \quad .002^{* *}$

$-1.22 \quad .224$

$-7.99<.001^{* *}$

$-16.62<.001^{* *}$

$-17.56<.001^{* *}$

Note. The higher the mean, the greater the stress level. The mean score range is 1 to 5 .

${ }^{*} p<.05,{ }^{* *} p<.01$

Similarly, the means of four of the five Stress Manifestations factors differed significantly between private and public schools. In each case public 
school teachers reported higher mean scores indicating higher levels of stress on these factors. Three of the factors, i.e., Emotional, Gastronomic, and Behavioral Manifestations are significant at the $p<.01$ level and Fatigue Manifestations is significant at the $p<.05$ level.

With significant differences on the Stress Source and Manifestations factors the total stress strength means for private and public schools are 2.27 and 2.60 respectively resulting in a mean difference of .33 and a $p$-value of $<.001$. This difference between total stress strength scores indicates that on-the-job stress is lower than average for private school teachers and higher than average for public school teachers. The means for both private and public school teachers, however, still fall within the moderate range.

Comparison of individual items means for private and public schools Moving beyond the subscale and total stress strength means, an analysis of the mean differences on many of the 49 individual items of the TS/ point to some very important findings and provides additional insights concerning the differences between public and private schools in specific areas.

As Table 10 indicates, of the 49 items on the TSI, 36 are significantly different, 34 at the $p<.01$ level and 2 at the $p<.05$ level. Only two of the item means on the Time Management factor for public school teachers were greater than teachers from private schools. As noted above, this is the only factor on which private school teachers report having a higher level of stress compared to 
teachers in public schools. These two items, "become impatient" and "do more than one thing at a time" have means of 3.10 and 3.60 respectively. This difference between private and public schools on the later item is particularly dramatic with the mean from private school being 3.05, a mean difference of .55 .

Table 10

Comparison of Private and Public Schools on Individual Items of Stress Sources and Manifestations

\begin{tabular}{|c|c|c|c|c|c|c|}
\hline \multirow[t]{2}{*}{$\begin{array}{l}\text { Item } \\
\text { no. }\end{array}$} & \multirow[t]{2}{*}{ abbreviated item stem } & \multicolumn{2}{|c|}{$\begin{array}{l}\text { private } \\
(\underline{n}=316)\end{array}$} & \multirow{2}{*}{$\begin{array}{c}\text { public } \\
(n=3401) \\
\underline{M}\end{array}$} & \multirow[b]{2}{*}{$\mathfrak{t}$} & \multirow[b]{2}{*}{$\mathrm{p}$-value } \\
\hline & & $\underline{\mathrm{M}}$ & $\mathrm{SD}$ & & & \\
\hline \multicolumn{7}{|c|}{ Time management } \\
\hline 1. & Easily overcommit myself & 3.41 & 1.03 & 3.20 & 3.71 & $<.001^{* *}$ \\
\hline 2. & Become impatient & 2.93 & 1.04 & 3.10 & -2.85 & $.005^{* *}$ \\
\hline 3. & Do more than one thing at a time & 3.05 & 1.37 & 3.6 & -7.15 & $<.001^{\star *}$ \\
\hline 4. & Have little time to relax & 3.88 & 1.10 & 3.7 & 2.94 & $.004^{* *}$ \\
\hline 5. & Think about unrelated matters & 2.80 & 1.17 & 2.80 & .06 & .953 \\
\hline 6. & Feel uncomfortable wasting time & 3.68 & 1.20 & 3.6 & 1.12 & .262 \\
\hline 7. & Not enough time to get things done & 4.10 & .99 & 3.5 & 10.79 & $<.001^{* * *}$ \\
\hline 8. & Rush in my speech & 2.72 & 1.27 & 2.4 & 4.44 & $<.001^{* *}$ \\
\hline \multicolumn{7}{|c|}{ Work-related stressors } \\
\hline 9. & Little time to prepare & 3.17 & 1.08 & 3.10 & 1.16 & .245 \\
\hline 10. & Too much work to do & 3.55 & 1.10 & 3.40 & 2.48 & $.014^{\star}$ \\
\hline 11. & School day pace is too fast & 3.04 & 1.19 & 2.70 & 5.05 & $<.001^{* *}$ \\
\hline 12. & Caseload/class is too big & 2.47 & 1.24 & 2.80 & -4.69 & $<.001^{* *}$ \\
\hline 13. & $\begin{array}{l}\text { Personal priorities are being } \\
\text { shortchanged }\end{array}$ & 3.50 & 1.21 & 3.30 & 3.01 & $.003^{* *}$ \\
\hline 14. & Too much administrative paperwork & 2.51 & 1.22 & 3.70 & -17.46 & $<.001^{* *}$ \\
\hline \multicolumn{7}{|c|}{ Professional distress } \\
\hline 15. & $\begin{array}{l}\text { Lack promotion/advancement } \\
\text { opportunities }\end{array}$ & 2.53 & 1.38 & 2.90 & -4.75 & $<.001^{* *}$ \\
\hline 16. & Not progressing rapidly in my job & 2.05 & 1.18 & 2.50 & -7.18 & $<.001^{* *}$ \\
\hline 17. & Need more status and respect & 2.40 & 1.32 & 3.00 & -8.17 & $<.001^{* *}$ \\
\hline 18. & Receive an inadequate salary & 3.26 & 1.40 & 3.70 & -5.54 & $<.001^{* *}$ \\
\hline 19. & Lack recognition & 2.84 & 1.40 & 3.70 & -5.83 & $<.001^{* *}$ \\
\hline \multicolumn{7}{|c|}{ Discipline and motivation } \\
\hline 20. & Discipline problems in classroom & 1.91 & 1.04 & 2.70 & -13.47 & $<.001^{* *}$ \\
\hline 21. & Having to monitor pupil behavior & 2.05 & 1.15 & 3.00 & -15.09 & $<.001^{* *}$ \\
\hline 22. & $\begin{array}{l}\text { Students who would do better if they } \\
\text { tried harder }\end{array}$ & 2.69 & 1.13 & 3.20 & -8.05 & $<.001^{* *}$ \\
\hline 23. & $\begin{array}{l}\text { Teaching students who are poorly } \\
\text { motivated }\end{array}$ & 2.29 & 1.13 & 3.20 & -16.28 & $<.001^{* *}$ \\
\hline 24. & $\begin{array}{l}\text { Inadequate/poorly defined discipline } \\
\text { policies }\end{array}$ & 1.75 & .96 & 2.70 & -17.6 & $<.001^{* *}$ \\
\hline 25. & $\begin{array}{l}\text { Authority rejected by } \\
\text { pupils/administrators }\end{array}$ & 2.05 & 1.25 & 2.70 & -9.17 & $<.001^{* *}$ \\
\hline
\end{tabular}


Professional investment

\begin{tabular}{|c|c|c|c|c|c|c|}
\hline 26. & $\begin{array}{l}\text { Personal opinions not sufficiently } \\
\text { aired }\end{array}$ & 2.13 & 1.15 & 2.60 & -7.20 & $<.001^{* \star}$ \\
\hline 27. & Lack control over decisions & 2.20 & 1.22 & 3.00 & -11.60 & $<.001^{* * *}$ \\
\hline 28. & $\begin{array}{l}\text { Not emotionally/intellectually } \\
\text { stimulated }\end{array}$ & 1.58 & .86 & 2.50 & -18.97 & $<.001^{\text {** }}$ \\
\hline 29. & Lack opportunities for improvement & 1.66 & .97 & 2.70 & -19.16 & $<.001^{* *}$ \\
\hline \multicolumn{7}{|c|}{ Emotional manifestations } \\
\hline 30. & Feeling insecure & 2.23 & 1.25 & 2.70 & -3.83 & $<.001^{* *}$ \\
\hline 31. & Feeling vulnerable & 2.21 & 1.21 & 2.40 & -2.74 & $.006^{* *}$ \\
\hline 32. & Unable to cope & 2.27 & 1.30 & 2.40 & -1.88 & .061 \\
\hline 33. & Feeling depressed & 2.35 & 1.27 & 2.80 & -6.25 & $<.001^{* *}$ \\
\hline 34. & Feeling anxious & 3.22 & 1.27 & 3.00 & 3.10 & $.002^{* *}$ \\
\hline \multicolumn{7}{|c|}{ Fatigue manifestations } \\
\hline 35. & Sleeping more than usual & 1.96 & 1.19 & 2.20 & -3.56 & $<.001^{\star \star *}$ \\
\hline 36. & Procrastinating & 2.34 & 1.26 & 2.60 & -3.61 & $<.001^{* *}$ \\
\hline 37. & Becoming fatigued in a short time & 2.66 & 1.30 & 2.60 & .82 & .412 \\
\hline 38. & Physical exhaustion & 2.95 & 1.35 & 3.00 & -.63 & .532 \\
\hline 39. & Physical weakness & 2.07 & 1.20 & 2.10 & -.49 & .626 \\
\hline \multicolumn{7}{|c|}{ Cardiovascular manifestations } \\
\hline 40. & $\begin{array}{l}\text { Feelings of increased blood } \\
\text { pressure }\end{array}$ & 1.88 & 1.31 & 1.90 & -.24 & .814 \\
\hline 41. & Feelings of heart pounding or racing & 2.08 & 1.30 & 2.10 & -.24 & .809 \\
\hline 42. & Rapid/shallow breath & 1.77 & 1.17 & 1.60 & 2.56 & $.011^{*}$ \\
\hline \multicolumn{7}{|c|}{ Gastronomical manifestations } \\
\hline 43. & Stomach pain of extended duration & 1.50 & 1.05 & 1.70 & -3.29 & $.001^{* *}$ \\
\hline 44. & Stomach cramps & 1.54 & 1.08 & 1.70 & -2.65 & $.008^{* *}$ \\
\hline 45. & Stomach acid & 1.76 & 1.30 & 1.90 & -1.85 & .066 \\
\hline \multicolumn{7}{|c|}{ Behavioral manifestations } \\
\hline 46. & Using over-the-counter drugs & 1.43 & .98 & 1.40 & .48 & .635 \\
\hline 47. & Using prescription drugs & 1.22 & .77 & 1.40 & -4.06 & $<.001^{* *}$ \\
\hline 48. & Using alcohol & 1.32 & .70 & 1.40 & -1.86 & .064 \\
\hline 49. & Calling in sick & 1.09 & .45 & 1.50 & -16.13 & $<.001^{* *}$ \\
\hline
\end{tabular}

Note. The higher the mean, the greater the stress level. The mean score range is 1 to 5 .

${ }^{*} p<.05,{ }^{* *} p<.01$

The means of items on the Time Management factor on which private school teachers report having greater stress are "easily overcommit myself," "have little time to relax," "rush in my speech," and "not enough time to get things done" In terms of the later, the mean for private school teachers is 4.10 and for 
public 3.50. This is one of the more substantial mean differences on the entire TSI.

With a mean difference of only .06 between public and private schools, on the Work-Related factor the two are not statistically significant. However, an item by item analysis reveals private and public school teachers report very different responses that tended to average each other out thereby masking some important differences. Of particular interest are the items "caseload/class is too big" and "too much administrative paperwork." The mean for private schools on the former is 2.47 and that for public schools, 2.80 , a difference significant at a $p<.001$ level. The teaching load and class size of private school teachers are generally smaller than their public school counterparts. For example, the average total number of students taught per day by private school teachers who participated in this study is 58 . For the item, "too much administrative paperwork" private school teachers register a mean of 2.51 while the mean for public school teachers is 3.70 , a mean difference of 1.19 , one of the highest on the entire inventory. Interestingly, despite the fact that public school teachers had higher means on caseload/class sizes and administrative paperwork, on the item "too much work to do" private school teachers have a mean of 3.55 as opposed to public school teachers with a mean of 3.40 .

Of the five items comprising the Professional Distress factor the teachers making up the public school sample reported significantly higher stress levels, all at the $p<.001$ level (see Table 10). In terms of contributing to on-the-job stress, 
iie lack of opportunities for professional advancement, inadequate status, respect and lack of recognition appear to have a greater impact on the stress level on public school teachers. A surprising finding is the fact that the item, "receive an inadequate salary," has a mean of 3.70 for public schools and 3.26 for private schools, a difference significant at $p<.001$. Although salaries in private schools are traditionally lower than in public schools this does not seem make as strong an impact on teachers in the private sector.

Another finding of note is the difference between public and private school teachers regarding status and respect. The mean for private school teachers on this items is 2.40 , while that of public school teachers is 3.00 . Clearly, private school teachers feel that they garner more status and respect as educators. Combined with other factors related to Professional Distress, this translates into significantly lower levels of stress for those teachers working in the private sector. This finding also raises questions regarding generalizations about the relatively low status with which teaching is held in today's society.

One of the research questions focused on the levels of stress that private school teachers would report regarding student discipline and motivation. Based on the research literature on public school teacher stress discipline and motivation emerge as noteworthy sources of stress. The findings indicate that on each of the six items comprising the Discipline and Motivation factor private school teachers have significantly lower means $(p<.001)$ on all of the items. On no other factor are the mean differences greater. On two of the items, "having to 
monitor pupil behavior" and inadequate/poorly defined discipline policies" the mean difference is .95 . As noted previously, the selective nature of the admissions process in private schools should be reflected in higher levels of student motivation. This appears to be borne out by results of this study. On this item on the TSI the means for private and public schools are 2.29 and 3.20 respectively, a mean difference of .91 .

The greatest mean difference between public and private schools occurs on the Professional Investment factor. On the item, "lack opportunities for improvement," the mean for private school teachers is 1.66 , while the mean for public school teachers is 2.70 , a mean difference of 1.04 . A similar situation exists for the item, "not emotionally/intellectually stimulated," with the means for private and public schools being 1.58 and 2.50 respectively. On the two other items of this factor, "personal opinions not sufficiently aired" and "lack control over decisions," private school teachers recorded significantly lower means reflecting the autonomy that this segment of the profession enjoys as well as a diminished bureaucracy making it easier to be heard.

On the Stress Manifestations factors the differences between private and public schools are far less dramatic. On the Emotional Manifestations factor the only item for which there is not a statistically significant difference is "unable to cope." Public school teachers record higher means on three of the other four items: "feeling insecure," feeling vulnerable," and "feeling depressed." The mean difference on "feeling depressed" is noteworthy with a significantly different mean 
of 2.35 for private school teachers versus 2.80 for public $(p<.001)$. A finding of some interest is that private school teachers report greater levels of anxiety than their public school colleagues. A possible explanation for this increased anxiety level may be that private school teachers feel a great sense of accountability because they operate in a system without tenure and guaranteed job security. With smaller class sizes, diminished teaching loads, and fewer problems regarding student discipline and motivations private school teachers are expected "to deliver." Parental expectations can be omnipresent contributing to higher levels of anxiety.

Of the five items making up the Fatigue Manifestations factor, public school teachers report significantly higher levels on two of the items, while three of the mean differences are not significant. More specifically, public school teachers indicated that they "sleep more than usual" and "procrastinate" more than their private school colleagues as a result of stress. Only one significant mean difference on the Cardiovascular Manifestations factor emerges. Teachers from the public sector report a mean of 1.60 as opposed to their private school colleagues who have a higher mean of 1.77 for "rapid/shallow breath."

In summarizing the findings of this study private school teachers exhibit low to moderate levels of stress in terms of student discipline and motivation. These teachers report similar levels of stress in terms of professional distress and professional investment as well. Finally, although work-related stress represented one of the greatest sources of stress the stress level is still within 
the moderate range. Overall, the profile of occupational stress level of these teachers places them in the lower than average range. When this profile is compared with public school teachers the difference is significant not only statistically but in the day-to-day lives of teachers in public schools as well. The mean score for these teachers falls within the higher than average range. Moreover, the sources of stress for public school teachers in some cases are considerably stronger than their colleagues in private schools, e.g., student discipline and motivation.

Comparisons between private schools based on the variable of school size reveal differences which are statistically significant, however, this difference does not translate into any substantial real difference in stress levels in the everyday lives of these teachers. Similar findings are in evidence when one compares boarding and day schools. 


\section{CHAPTER 5}

\section{Discussion of Findings}

The purpose of this study was threefold. The primary purpose was to develop a stress profile for teachers in private schools. Within this context four research questions were identified and tested. This study also addressed two exploratory questions. The first was to examine possible differences in the levels of on-the-job stress among teachers in different types of private schools. A second issue was to discuss the findings on private schools in light of the extant literature on public schools, specifically using the data collected by Fimian collected in developing the Teacher Stress Inventory.

Question \#1: What levels of stress do private school teachers experience in terms of student discipline and motivation?

Student discipline and motivation, particularly discipline, emerge again and again in the literature as compelling sources of teacher stress. This is the case even in the paucity of studies conducted on private schools. Solman and Feld's (1989) study of stress in Catholic school in New South Wales revealed that student discipline ranked second in terms of what stressed them the most. Nearly a quarter of Catholic school teachers indicated that student discipline problems generated considerable stress. In a study of nondenominational private schools in Victoria, Australia Pierce and Molloy (1990) found that over 18 percent of teachers rated "Student problems, demands, and behavior" as the 
Ineir greatest sources of stress. Unfortunately, similar studies do not exist for private school teachers in the United States.

This question is rooted in the assumption that a more selective admissions process and the ability to dismiss students who present themselves as discipline problems would translate into lowers levels of stress in private school teacher on the Discipline and Motivation factor. A mean of 2.12 on this subscale puts it at the bottom of the range for moderate stress $(1.90$ to 4.00$)$ and very close to the significantly low range. In addition, of the five Stress Source factors, the one regarding student discipline and motivation ranked fourth.

The data results for individual items point to the fact that student motivation represents a greater source of stress than discipline. For example, the items on discipline problems in the classroom and having to monitor pupil behavior recorded means of 1.91 and 2.05 respectively with a rating of 2.00 representing "mild strength" or "barely noticeable" The means for items on this factor climb somewhat, however, when one examines the two items related to student motivation. The mean for the item, "I feel frustrated because some students would do better if they tried." is 2.69 . The item, "I feel frustrated teaching students who are poorly motivated" has a mean of 2.29. These findings point to the possibility that motivation issues may present a greater source of stress than discipline problems and suggest further research is needed to determine if this is the case. In addition researchers may want to explore in 
more detail teacher attitudes regarding student discipline and motivation in private schools. Why do teachers feel that students are not trying harder?

The remaining two items on this factor reveal something about the nature of private schools. The way discipline is framed in private school may help alleviate stress in this area. The item regarding inadequate or poorly defined discipline policies has a significantly low mean $(M=1.75)$ indicating that both teachers and students are clear in terms of where they stand regarding what constitutes acceptable behavior. This item had the lowest mean of the six items comprising this factor. Similarly, the item, "I feel frustrated when my authority is rejected by pupils/administration" ( $M=2.05)$ falls in the "mild strength" or "barely noticeable" range. In all likelihood the teachers relatively low rating of this item has implications for other potential stressors as well. For example, the literature is clear in terms of indicating that support from administrators can go a long way in tempering teacher stress (Sarros \& Sarros, 1992; Courtney, 1988; Schwab, Jackson, \& Schuler, 1986; Gupta, 1981). Similarly, role ambiguity contributes to teacher stress (Bacharach, Bamberger, \& Mitchell, 1991; Pierson, 1983; Schwab \& Iwanicki, 1982a). When lines of authority are understood and respected, and supported stress is lessened. Finally, support from administrators and students regarding authority may contribute to teachers needs for respect and status. As the findings from this study suggest, support from colleagues and admininstration may represent an important component of 
the culture of private schools. When asked "Do you and your peers support one another when needed?" $97.3 \%$ of the teachers responded "Yes." When asked a similar question about their supervisors, $93.6 \%$ of the teachers responded in the affirmative as well. To receive such a positive response in such large numbers, i.e., 316 teachers, may point to one of the defining elements of private school culture and warrants additional research. What are the dynamics in private schools such that a large majority of teachers feel supported by principals and fellow teachers?

Question \#2. What levels of on-the-job stress do private school teachers experience in terms of personal distress, i.e. promotion opportunities. inadequate salary, status and respect, and recognition?

The data from this study (see Table 5) suggest that private school teachers experience moderate levels of stress in terms of professional distress. A mean between 2.00 and approximately 4.10 represents a moderate level of stress on the TSI. Of all the factors for Stress Sources, Professional Distress ranked second $(M=2.62)$.

Salary has been identified as a source of stress for educators. In their reviews of the literature both Kyriacou (1987) and Turk, Meeks, and Turk (1982) noted that inadequate salary is a source of teacher stress. Moreover, in the case of private school teachers, their salaries frequently lag behind those of their public school counterparts. Of the individual items on the Professional Distress 
factor, that with the highest mean is concerned with an inadequate salary $(M=3.26)$ (see Table 10). This item also had the largest $S D(1.40)$ of all of the individual items on the TSI. While higher than other items, inadequate salary still falls comfortably into the moderate range, a result not anticipated in this study.

Two possible explanations emerge. The first is that teachers in private schools may be secondary income earners and, therefore, salary may not be as significant an issue among private school teachers. The second has two dimensions. Both relate to the model for stress presented in Chapter 2. That model has four basic components. The first is the particular stressor expereinced by the teachers. The second element is the teacher's perception of the stress. As Freisen (1986) noted in his discussion of stress, perception is a critical component in understanding the dynamics of stress. "The perceptions of the demands made on an individual by a stressor is an important aspect of what happens in the stress cycle" (p. 10). Interconnected with perception are the resources that the teacher possesses to deal with stress. The combination of perception and resources determine the teacher's response to the stressor. Teachers working in the profession in private schools may simply perceive that the salary differential is a trade off for other advantages such as class size, greater classroom autonomy, higher levels of student motivation, tuition remission, and fewer discipline issues. 
Another explanation for the lower stress levels regarding salary may be reflected in the work of Needle, Griffin, and Svendsen (1981) who suggest that teacher stress arises from "descrepancies between work values and occupational rewards available from the school environment" (p. 176). Private school teachers may enter the profession expecting to earn less than their public school colleagues knowing that other positive features of teaching in private schools balance out the public/private school salary differential. As a result, these teachers do not experience such a large descrepancy in terms of their occupational rewards, including salary. If this is the case, perception again comes into play. Teachers see a diminished salary as a tradeoff for other factors such as classroom autonomy, smaller class sizes, thus affecting their . perception of salary as a source of stress.

"Lack of recognition" also generated one of the higher means among the individual items of this factor $(M=2.84)$. It is interesting to note that this item differs significantly from that of public school teachers $(M=3.30)$. Stress resulting from lack of recognition may be more a function of the size of the organization than the nature of the enterprise. However, with smaller teaching populations it may simply be easier for administrators to recognize the good work that teachers do. At this researcher's school, for example, the head routinely writes personal notes of thanks to teachers and recognizes special achievements at faculty meetings. In their research Blase and Kirby (1992) have noted that one of the 
characteristics of effective principals is to thank teachers for the good work that they do. The administrator with 16 teachers as opposed to 160 has a far better chance of doing this.

Considerable attention has been focused on the poor status of teaching as a profession. Esteve (1989) has even linked the poor status of teaching to a society which tends to base social status on income where once the notions of self-sacrifice and vocation were highly valued. The private school mean for this item, "I need more status and respect on my job," is 2.40 , indicating that this is a moderate stressor. Extending Esteve's logic, poor status among teachers should be even greater when one considers that the constituencies of private nondenominational schools tend to be of a higher socioeconomic status when compared with the general population. In all likelihood the issue of status and respect among private school teachers is a complex one. Despite private school teachers feeling at times that they are simply "the hired help," both parents and students alike have very high expectations of them. On one hand, this can be a source of stress. On the other, it may confer on these teachers a level of status and respect in as much as these teachers are entrusted to provide a high level of education for which parents pay considerable dollars (in some cases as much as $\$ 12,000$ or more for a day school) above the tax dollars they provide for public education. 
Lack of promotion and advancement opportunities has also received serious attention in the literature (Farber, 1984; Calabrese and Anderson, 1986; Cunningham, 1983). Yet, it does not seem to be a major source of professional distress for private school teachers $(M=2.53)$. It ranked 15 th of the 49 items on the TS/ for private school teachers (see Table 6). Again, a contributing a related issue may have to do with the questions of income. Cunningham (1983) suggests that administration represents an avenue for greater prestige and money for teachers. In other words, one of the attractions for teachers in the public sector to go into administration is pecuniary. If salary is less of an issue and source of stress for private school teachers then advancement may represent less of an attraction. Here, the idea of perception may be at play as well. Private school teachers, wishing to remain in the private sector because they feel that it offers certain advantages over the public sector may simply recognize the possibilities for advancement are limited resulting in a diminished source of stress.

Question \#3. What are the stress levels of private school teachers based on professional investment, i.e. classroom autonomy, opportunities to air personal opinions. opportunities for professional growth, intellectual emotional stimulation.

The mean for this factor for private school teachers is 1.97 , the lowest of all of the Stress Sources factors on the TSI. And while it is near the lower end of the moderate range it does not fall within the significantly low level range. In 
his study of the qualities valued by private school heads and teachers Cookson (1980) found that both ranked knowledge, intellectual independence and autonomy as desirable qualities. In addition, given an opportunity to rank the importance of eight statements both school teacher and administrator alike ranked, "Teachers should be free to speak publicly on important social issues" first. The findings of this study suggest that these attitudes may be reflected in diminished stress levels of private school teachers on the Professional Investment factor of the TSI. The items means ranged from 1.58 to 2.20 , all relatively low. "I am not emotionally/intellectually stimulated on the job" has a mean of 1.58 , one of the lowest means, 43 rd out of 49 items on the TSI. The high degree of intellectual stimulation that private school teachers seem to experience may be rooted in a tradition that values knowledge in one's subject area over education courses. Many private schools, for example, require teachers to hold a degree in field, or certification. Expertise of an intellectual nature is valued and reflected in independent study courses where students work with a teacher in a specialized area. Recently, at this researcher's school a teacher and high school student researched, wrote, and presented a paper at professional conference. In addition, less time dealing with paperwork and discipline problems may also afford more time with one's subject. Moreover, private school teachers are not held accountable to multitudinous curricular objectives mandated by state boards of education. Collectively, these factors 
explain why intellectual stimulation appears to be an important and highly valued part of the professional life of private school teachers.

The suggestion that private school teachers enjoy a good degree of autonomy is again supported by the item on lack of control of decisions with a mean of $2.20(2.00=$ "mild strength" or "barely noticeable"). Similarly, the lack of opportunities for airing personal opinions does not seem to generate much stress for teachers in private schools $(M=2.20)$ reflecting Cookson's study. While professional growth budgets in private schools are probably smaller than those in public schools, private school teachers do not seem to lack opportunities for improvement $(M=1.66)$. Private school teachers may find greater support for individual initiatives in terms of their own growth in an environment in which intellectual stimulation is valued. For example, at this researcher's school teachers can receive mini-grants for summer study and research on integrating the city of Miami into the curriculum. Similarly, one of the admininstrators has been instrumental in helping new foreign language teachers apply for and receive fellowships to study abroad. There is also a tendency for private schools to hire from within. Therefore, when growth opportunities become available, such as being a team leader or department head, the position frequently goes to an individual at the school who has shown promise.

The fact that the Professional Investment factor is the lowest of all the Stress Sources factors and the low means of all of the individual items speaks to 
the possibility of a fairly distinct private school culture which ameliorates on-thejob stress in these schools as compared to similar variables in public schools.

Question \#4: What are the stress levels experienced by private school teachers in terms of work-related stress i.e. lack of time for preparation. pace of the school day, shortchanging of personal priorities in light of time demands.

The literature on work related stress among public school teachers is abundant. Among those issues that have been explored include role overload, time pressures, and large classes (Manera \& Wright, 1980, Gupta, 1981; Needle, Griffin, \& Svendsen, 1981; Blase, 1986, Okebukola \& Jegede, 1992). Though few in number, the studies conducted on private schools suggest that private school teachers experience a high degree of work related stress as well. Although it averaged the second highest mean of all of the TSI subscales $(M=3.04)$, this is still very much within the moderate stress range for this subscale. Private school teachers frequently have additional duties and additional time commitments, i.e., lunch and break supervision, afternoon tutorials, that their colleagues in public school do not have. This is not necessarily translated into higher levels of stress, however. The difference between public and private school teachers on this subscale is .06 , a mean difference not statistically significant. Five of the six items on the Work-Related Stressors subscale have means exceeding 3.00 , i.e., "medium strength" or "moderately noticeable." The items "There is too much work to do" $(M=3.55)$ and 
"My personal priorities are being shortchanged due to time demands" $(M=3.50)$ have the highest means for items on this subscale and these fall in the midrange for moderate strength.

As would be expected stress related to number of students taught and class size $(M=2.47)$ and administrative paperwork $(M=2.51)$ are modest. These two factors make work in the private school more "teacher friendly" as teachers with classes of 18-20 students and far fewer forms and reports to complete have more time to spend on teaching and can work with students on a more individualized level. Despite smaller class sizes, fewer students, and modest amounts of paperwork, the private school teachers appear to have a fairly fast paced school day with little time to waste. The items regarding lack of preparation time and the pace of the school day being too fast have means of 3.17 and 3.04 respectively. While still in the moderate range they are sufficiently high enough to suggest that these two factors make an important contribution to the total stress of the private school teacher.

Beyond the data findings related to the four research questions are the other six factors comprising the TSI and how they contribute to the development of a profile of stress in private schools. Time Management represents the greatest contributor to teacher stress in private schools. Of all the factors it has the highest mean $(M=3.32)$. Clearly, teachers derive a noteworthy amount of stress from the fact that they do not have enough time during the day, a finding 
that should be noted by private school administrators. Of the 49 items making up the TSI, the highest is "There isn't enough time to get things done" $(M=4.10)$ indicating "great strength" or "very noticeable." This shortfall in time is reflected in another item on the Time Management factor. "I feel uncomfortable wasting time" has a mean of 3.68. Because private school teachers feel that they do not have enough time to get things done they "become impatient if others do things too slowly" ( $M=2.93)$, "think about unrelated matters during conversations" $(M=2.80)$, "rush in their speech" $(M=2.72)$, and "try to do more than one things at a time" $(M=3.05)$. As noted previously, private school teaching carries with it a number of additional responsibilities, e.g., monitoring students during break and lunch, offering tutorials. The stress levels of teachers in the private sector appears to reflect these additional responsibilities as the data from Time Management factor indicates.

The factors on Stress Manifestations tend to be lower than the factors for Stress Sources. All fall within the moderate range (see Table 5). With the exception of "feeling anxious" all of the means for the individual times fall below 3.00 (see Table 10). In terms of stress then, the moderate levels of sources of stress translate into a fairly moderate impact on the well being of private school teachers. This is good news. With the exception of experiencing anxiety $(M=3.22)$, these teachers cope well, maintain an energetic pace, and do not experience too much discomfort in terms of heart irregularities and stomach 
problems. As a rule there is not a great deal of reported reliance on pharmaceuticals or alcohol in order to deal with stress. Moreover, private school teachers rarely rely on calling in sick to deal with stress. All of these findings are encouraging when one considers the implications of stress for one's health.

\section{Discussion of Differences in Types of Private Schools}

As noted in Chapter 4 the total mean for stress strength for the private school teachers who participated in this study indicates an average or moderate level of stress. Moreover, on all of the factors on stress sources and manifestations these teachers fall into the moderate range. In addition, while a number of data findings emerge in comparing private schools by type, these statistical differences do not generally translate into very large differences in terms of the stress levels of teachers. The comparison of boarding and nonboarding school yields a statistical difference only on the Time Management subscale. At first glance, these finding are at odds with Dey's (1982) and Cohen's (1982) suggestions that boarding schools are particularly stressful. One possible explanation is that the population sample in this study represents both faculty who live on campus and those who do not. An area for possible research in the future would be to conduct a study with a number of boarding schools. Comparisons could be made between the TSI scores of those teachers who 
reside on campus, those who actually live in the dorms with students, and those teachers who live off campus. Additional research might focus on possible differences between teachers who are employed in single-sex and coeducational boarding schools.

The comparison of private schools by size presents some interesting findings. While significant differences occur on 8 of the 10 factors, most of these differences are between medium size and large schools. One would expect that if school size affects the stress level of teachers the differences would be found between the small and large schools, but this is not the case. What the data reveal is that teaching in a large private school is more stressful than small and medium schools with the greatest difference being with medium schools. However, the means for total stress strength for all three types of schools are well within the moderate range and the measurable difference between them translates into a very small difference in terms of the real stress levels of these teachers in their day-to-day lives. From a broader perspectives these findings suggest that private schools share a certain culture which transcends the size of the school.

It should be noted that all of the schools which participated in this study meet certain criteria which would probably have some very important implications for teacher stress. All were characterized by strong leadership, sustained enrollments and good financial standing. The presence of social support has 
been tied to lower levels of stress. As noted above, the vast majority of the teachers who completed the TSI in this study indicated that they felt supported by fellow teachers and administrators alike. This support most certainly translates into reduced stress levels among these teachers compared to public school teachers.

One of the limitations of this study is the absence of any single sex schools. Additional research is needed in this area. Private schools represent one of the few avenues left for students seeking an education exclusively with peers of their own gender. Given the interest in recent years on gender differences in the classroom it would be very interesting to see if single sex schools, both male and female, present any differences in terms of on-the-job stress for teachers in these schools. Because the population sample in this study is sufficiently large $(n=316)$ it can be used to provide baseline data. A future research question can focus on whether there are significant differences in the levels of stress of teacher who work in coeducational schools and those who teacher in single sex schools.

This study examined the levels of stress for only one segment of the private school population, i.e., large numbers of private schools that are religious were not included in this study. Catholic, Quaker, Lutheran, Epicopalian, conservative Christian, and Jewish schools represent a particular ethos and consequently a different school culture. What effects this culture may have on 
teacher stress is worthy of further study and should provide fertile ground for future research. Still, another experiment in the privatization of education are the charter schools. As noted in Chapter 1 their numbers are growing yearly. Again, using the results of this study as a baseline, additional research questions can focus on possible differences between the levels of stress of teachers in religious and nondenominational schools. In addition, are there differences in stress levels between the different types of religious schools? Do teachers in conservative Christian schools, for example, expereince levels of stress that vary from those who work in Catholic schools?

\section{Comparison of Private and Public Schools}

When the data from this study is compared with that of the public school teachers who participated in the development of the TSI, the differences are considerable both in terms of total stress strength and on most of the factors as well. While the mean for the total stress construct for the 316 private school teachers who completed the inventory is 2.27 , that for public teachers is greater at 2.60 , a difference significant at $p<.001$ level. As noted previously, of the 49 items comprising the TS/ private and public schools are significantly different on 37. This resulted in significant differences on the factors as well. However; when one looks beyond simply the statistical differences it is the differences on the stress sources that represent the most important differences, more specifically Professional Distress, Discipline and Motivation, and Professional 
Investment. In each case the lower means are found on the private school side of the ledger. And, while private schools have far greater control over the students they accept, there are perhaps lessons that can be learned from private schools and applied in the public sector.

In terms of Professional Distress, public school teachers indicated the issues of status and respect and recognition made substantially higher contributions to their levels of stress than in private schools. While it is difficult to change the way society views its teachers, changes within schools themselves are possible. The work of Blase and Kirby (1992) points to very real and practical strategies administrators can employ to make teachers feel better about what they do in both private and public schools. Respect, at least from administrators, should be forthcoming no matter what the school setting.

The private school will always enjoy a comparative advantage over its public school counterpart in terms of student discipline and motivation. This advantage is rooted in two factors. Private schools have a selective admissions process. While this in and of itself does not necessarily guarantee high levels of motivation it certainly is a contributing factor. Students applying to private schools often must go through a personal interview and take a series of entrance tests before being considered for admissions. In addition, they are often asked why they are interested in attending the school to which they are applying. Part of the admission process is the assessment of an applicant's level of motivation. 
Secondly, private schools have the luxury of asking students to leave the school if they demonstrate an unwillingness to abide by the discipline policies of the school. For example, at this researcher's school there is a "zero tolerance" drug policy. Any student caught possessing or using drugs on campus is automatically dismissed from the school.

The data from this study point to some lessons that public schools might derive from private schools to help alleviate stress. The difference between private and public schools on the item regarding inadequate/poorly defined discipline policies is .96 . Public schools would perhaps benefit from a reexamination of the policies that guide discipline procedures. Similarly, there are very real differences between public and private school teachers on the issue of authority being rejected by pupils and administrators. This issue goes directly to the question of support.

In terms of Professional Investment, the differences between stress sources of public and private school teachers is not only statistical but very real in the everyday lives of teachers. Private school teachers clearly feel that they have greater control over the decision making process. They also feel more emotionally and intellectually stimulated and see greater opportunities for improvement. Issues of stress can be addressed by a re-examination of school leadership. Ultimately, some of the answers to making stress more manageable for teachers may lie with the broader issue of the politics of reforming 
educational administration. In their essay "Making Schools Manageable: Policy and Administration for Tomorrow's Schools" Sykes and Elmore (1989) point out that many of the problems with educational reform develop because people are made to fit institutions instead of fitting institutions to people. In their reexamination of leadership they make some very important suggestions for making schools more manageable which would translate into less stress for teachers in terms of their professional investment. Two of their proposals are worth examining in detail.

Noting that the way principals are selected very often has little to do with the role that they perform, Sykes and Elmore advance the principle of uncoupling leadership from role. The wisdom of this approach is to allow varying kinds of leadership to emerge depending on the kind of school and the types of individuals who make up the faculty and administration. A drawback of this approach is that "It scares policy makers and central administrators who equate uniformity and control with quality" (p. 87). But, what of the advantages? Sykes and Elmore write:

Leadership would emerge through a variety of channels in different organizational forms. The instructional leader envisioned by the literature on principals might emerge through the traditional structure, leaving some residual informal leadership cadre of teachers. The senior teacher who commands loyalty and support 
from his or her colleagues as primus inter parus might emerge in the managing partner model. A leadership clique, with mutual aims and interests, might emerge in the building manager model. And the consumer model would combine professional leadership with community leadership (p.87).

Therefore, Sykes and Elmore suggest uncoupling leadership from role which might generate even more kinds of managerial and leadership structures creating "opportunities for people to work in organizations that correspond to their view of professional responsibility and leadership" and providing for "leadership structures that represent distinctive points of view about instructional practice" (p. 87).

Sykes and Elmore's insight has clear applicability in terms of professional investment as a source of teacher stress. In allowing the organization to mold itself to the individual, teachers have greater control over the decision making process, more room for emotional and intellectual stimulation, and increased possibilities for opportunities for improvement based on their talents and interests, rather than simply conforming to requirements for professional growth that may have little to do with their personal vision of what education should be.

An additional insight shared by these two researchers which has clear implications for diminishing the stress occasioned by professional investment issues is to reduce the complexity of the authorizing environment. Here Sykes 
and Elmore note that the most efficient form of regulation is self-regulation. They note that many policies regarding school are predicated on the assumption that "schools will invariably do the wrong thing unless they are told to do the right thing." Virtually every aspect in the life of a school, and therefore teachers, is prescribed from the selection of textbooks, to the administration of tests, to how student progress/learning is to be measured and evaluated. "The authorizing environment of schools--that collection of rules, processes, and hierarchical structures designed to control the behavior of people," they write, "is so crowded with requirements, and the enforcement of those requirements is so idiosyncratic, that school people are forced to sample and select in order to survive" (p. 89). Interestingly, this approach is at considerable odds with private schools where teachers enjoy a considerable amount of autonomy, e.g., textbook selection and evaluation procedures.

\section{Recommendations for Managing Teacher Stress}

If this study suggests that public schools might learn some lessons regarding alleviating stress from the private sector, the profile of private school teacher stress suggests that administrators of private schools might take note as well. One of the most important things that administrators in the private sector should do is learn more about occupational stress and how it affects their teachers and schools. The dearth of research on private schools may be indicative of a lack of interest in this topic. If this is the case, administrators 
should take note. The TSI represents an excellent opportunity for them to explore their own institutions in terms of stress. The subscale and individual item analyses can provide principals and other administrators with invaluable data about their schools and how their teachers are responding to the day-to-day demands of teaching. As more and more organizations are learning the benefits of wellness programs, helping teachers understand and manage occupational stress can make a tremendous contribution to the life of a school.

This study also suggests that private schools might benefit from a reexamination of what teachers are asked to do and how much time they are given to complete tasks. Good teaching is "labor intensive" and expectations from teachers in private school may be too much in some cases. At the very least, time management strategies might be offered as in-service training particularly as part of the orientation for new teachers who must fast the additional pressures and stress associated with starting a career.

Finally, all administrators, both public and private should note Kyriacou's (1987) observation regarding teacher stress. While acknowledging that the sources of stress vary for any individual teacher or particular school, he writes that "it is perhaps the general level of alertness and vigilance required by teaching in meeting the potentially threatening variety of demands made upon them." Kyriacou suggests that this is "the essence of why the experience of stress and burnout" have become so prevalent in the profession. One of the 
best ways for administrators to counter these conditions is by extending their trust and support to their teachers on a daily basis.

\section{Recommendations for Future Research}

Considerable research on teacher stress in private schools remains to be done. Given the number of teachers in private schools and the issue of privatization on the educational horizon there may be lessons yet to be learned. This study included only one boarding school. A more extensive study focusing exclusively on this kind of school might prove beneficial. Likewise, studies incorporating Catholic schools are few in number and have been conducted abroad. Quaker, Catholic and other denominational schools, as well as Christian and Jewish schools, represent educational institutions with a particular ethos. Is stress different in these schools? No research was found on private single sex schools. Clearly, this is an area of research that warrants attention.

The data from this study suggest other questions that might be addressed by future research as well. For example, despite the fact that salary has been identified as an important source of teacher stress, why is this not the case in private schools? Is it a question of school culture or a characteristic of the private school teaching population. Research might focus on the numbers of private school teachers who derive their primary and secondary incomes from teaching.

While this study focused on the development of a profile of occupational 
stress in private schools, there are considerable opportunties for looking at stress on a more individual level and the realtionship between stress and personality issues. As noted previously, some research has focused on personality type and levels of stress. Future studies might examine issues such as locus of control, self-esteem, and other personality issues and how these factors and stress might relate to each other.

Another avenue of research might examine possible sources of stress that are more characteristic of private than public schools. For example, in a series of interviews conducted by this student with private school teachers, parents were identified as a particularly significant source of stress by teachers. Similarly, research might focus on factors in privates schools that have a mitigating effect on stress as in the case of support from administrators and colleagues. As noted earlier, the vast majority of the teachers that participated in this study indicated that they enjoyed support from both teachers and supervisors alike and that they offered support when needed. 


\section{List of References}

Abernathy, S., Manera, E., \& Wright, R.E. (1985). What stresses Student teachers the most? Clearning House. 58 (8), 361-362.

Alley, R. (1980). Stress and the professional educator. Action and Teacher Education, 4 (2), 1-8.

Alschuler, A.S., Carl, J., Leslie, R., Schweiger, I., \& Uustal, D. (Eds.). (1984). Teacher bumout. Washington, DC: National Educational Association.

Bacharach, S.B., Bamberger, P., \& Mitchell, S. (1980). Work design, role conflict, and role ambiguity: The case of elementary and secondary schools. Educational Evaluation and Policy Analysis, 12, 415-432.

Bacharach, S.B., Bauer, S.C., \& Conley, S. (1986). Organizational analysis of stress: The case of elementary and secondary schools. Work and Occupations, 13, 7-32.

Bensky, J.M., Shaw, S.F., Grouse, A.S., Bates, H., Dixon, B., \& Beane, W.E. (1988). Public Law 94-142 and stress: A problem for educators.

Exceptional Children, 47, 24-29.

Billingsley, B.S., \& Cross, L.H. (1992). Predictors of commitment, job satisfaction, and intent to stay in teaching: A comparison of general and special educators. Joumal of Special Education, 25, 453-471.

Blase, J.J. (1986). A qualitative analysis of sources of teacher stress: Consequences for performance. American Educational Research Joumal, 23, $13-40$. 
Blase, J.J. (1984). School principals and teacher stress: A qualitative analysis. National Forum of Educational Administration and Supervision, 1 (2), $35-43$.

Blase, J.J. (1982). A social-psychological grounded theory of teacher stress and burnout. Educational Administration Quarterly, 18, (4), 93-113.

Blase J. \& Kirby, P.C. (1992). Bringing out the best in teachers: What effective principals do. Newbury Park, CA: Corwin Press.

Borg, M.G., \& Riding, R.J. (1991). Towards a model for the determinants of occupational stress among schoolteachers. European Journal of Psychology of Education, 6, 355-373.

Braaten S.L. (1990). Role-related stress in special education teachers of students with emotional and behavioral disorders. Dissertation Abstracts International, 52, (02), 355A.

Byrne, B.M. (1991). Bournout: Investigating the impact of background variables for elementary, intermediate, secondary, and university educators. Teaching and Teacher Education, 7, 197-209.

Calabrese, R.L., \& Anderson, R.E. (1986). The public school: A source of stress and alienation among female teachers. Urban Education, 21 (1), 30-41.

Capel, S. (1989). Stress and burnout in secondary school teachers:

Some causal factors. In M. Cole \& S. Walker (Eds.), Teaching and stress (pp. 36-48). Philadelphia: Open University Press. 
Cedoline, A.J. (1982). Job burnout in public education: Symptoms, causes, and survival skills. New York: Teacher College Press.

Center for Education Reform. (1996). Charter school statistics.

Washington, DC: Center for Education Reform.

Cichon, D.J., \& Koff, R.H. (1980). Stress and teaching. NASSP Bulletin, 64 (434), 91-104.

Cohen, J. (1988). Statistical power analysis for the behavioral sciences. 2nd edition. Hillsdale, NJ: Lawrence Erlbaum.

Cohen, J.A. (1982). Stress and the boarding school teacher. Independent School, 41 (3), 49-50.

Cole, M., \& Walker, S. (1989). Teaching and stress. Philadelphia: Open University Press.

Connors, D.A. (1983). The school environment: A link to understanding stress. Theory into Practice, 22, 15-20.

Cookson, P.W. (1980). The educational attitudes of private educators. Paper presented at the annual meeting of the American Sociological Association, New York, NY. (ERIC Document Reproduction Service No ED 013 499).

Courtney, M.B. (1988). The relationship between the perceived degree of instructional leadership and principal management style and teacher stress. Dissertation Abstracts International, 44, (01), 17-18A. 
Cox, T., \& Brockley, T. (1984). The experience and effects of stress in teachers. British Educational Research Joumal, 10, 83-87.

Cunningham, W.G. (1983). Teacher burnout--solutions to the 1980s: A review of the literature. Urban Review, 15, (1), 37-51.

Dedrick, C.V.L., \& Raschke, D.B. (1980). The special educator and job stress. Washington, DC: National Education Association.

DeMoulin, D.F., (1991). Stress be not proud: The myth of burnout. Journal of School Leadership, 1, 140-154.

Dewe, P.J. (1986). An investigation into the causes and consequences of teacher stress. New Zealand Joumal of Educational Studies, 21 (2), 145-157.

Dey, C.F. (1982). The stress of ambiguity. Independent School, 41 (3), 47-49.

Dworkin, A.G., (1987). Teacher bumout in the public schools: Structural causes and consequences for children. Albany: State University of New York Press.

Eskridge, D.H., \& Coker, D.R. (1985). Teacher stress: Symptoms, causes, and management techniques. Clearing House, 58 (9), 387-390.

Farber, B.A. (1984). Stress and burnout in suburban teachers. Journal of Educational Research, 77, 325-331.

Feitler, F.C., \& Tokar, E. (1983). Getting a handle on teacher stress: How bad is the problem? Educational Leadership, 39, 456-458.

Fimian, M.J. (1982). What is teacher stress? The Clearing House, 56, 
101-106.

Fimian, M.J. (1983). An analysis of the relationship among personal and professional variables and perceived stress of mainstream and special education teachers. Dissertation Abstracts International, 43,

Fimian, M.J. (1988). Teacher Stress Inventory. Brandon, VT: Clinical Psychological Publishing Co.

Friesen, D. (1986, April). Overall stress and job satisfaction as predictors of burnout. Paper presented at the annual national conference of the American Educational Research Association, San Francisco, CA. (ERIC Document Reporduction Service No. ED 274 698)

Friesen, D. \& Richards, D. (1984). Paper presented at the annual conference of the American Educational Research Association, New Orleans, LA. (ERIC Document Reproduction Service No. ED 253 942)

Goodall, R., \& Brown, L. (1980). Understanding Teacher Stress. Action and Teacher Education, 4 (2), 17-21.

Greer, J.G., \& Greer, B.B. (1992). Stopping burnout before it starts: Prevention measures at the preservice level. Teacher Education and Special Education, 15 (3), 168-174.

Gupta, N. (1981). Some sources and remedies of work stress among teachers. Paper presents at the annual conference of the National Institue of Education, Washington, DC. (ERIC Document Reproduction Service No. ED 211 
Gupta, N. \& Jenkins, D.C. (1981). Work role stress among female and male public school teachers. Paper presented at the annual conference of the American Psychological Association, LosAngeles, CA. (ERIC Document Reproduction Service No. 211497 )

Hamann, D.L. (1990). Burnout: How to spot it, how to avoid it. Music Education Journal, 77 (2), 30-33.

Hutchinson, L.R. (1990). A study of perceived sources of stress and degrees of stress among chief executive officers in California's private, nonsectarian schools. Unpublished doctoral dissertation, Northern Arizona University.

Iwanicki, E.F. (1983). Toward understanding and alleviating teacher burnout. Theory into Practice, 22, 27-32.

Jersild, A.T. (1955). When teachers face themselves. New York: Teachers College Press.

Johnson, J.H. (1986). Life events as stressors in childhood and adolescence. Newbury Park, CA: Sage

Kaiser, J.S., \& Polczynski, J.J. (1982). Educational stress: sources, reactions, preventions. Peabody Journal of Education, 59, 127-136.

Klanderman, S. J. E. (1985). A study of teacher stress and principal leadership styles in private urban schools. Unpublished doctoral dissertation, Columbia University Teachers College of New York. 
Kyriacou, C. (1989). The nature and prevalence of teacher stress. In M. Cole \& S. Walker (Eds.), Teaching and stress (pp. 27-34). Philadelphia: Open University Press.

Kyriacou, C. (1987). Teacher stress and burnout: An international review. Educational Research, 29, 146-152,

Kyriacou, C., \& Sutcliff, J. (1978). Teacher stress: Prevalence, sources, and symptoms. British Journal of Educational Psychology, 48, 159-167.

Lazarus, R.S. \& Folkman, S. (1985). Stress, appraisal, and coping. New York: Springer Publishing.

Litt, M.D., \& Turk, D.C. (1985). Sources of stress and dissatisfaction in experienced high school teachers. Joumal of Educational Research, 78, 178185.

McIntyre, T.C. (1981). An investigation of the relasionship among burnout, locus of control, and selected personal/professional factors in special education teachers. Dissertation Abstracts International, 42 (09), 3949A.

Malik, J.L., Mueller, R.O., Meinke, D.L. (1991). The effects of teaching expereince and grade level taught on teacher stress: A Lisrel Analysis. Teaching and Teacher Education, 7, 57-62.

Manera, E., \& Wright, R.E. (1980). Stress factors in teaching. Action and Teacher Education, 4 (2), 51-55.

Manlove, E.E. (1994). Conflict and ambiguity over work roles: The 
impact on child care worker burnout. Early Education and Development, 5, 4155.

Maples, M. F. (1980). Stress: In defense of its positive dimensions. Action and Teacher Education, 4 (2), 23-28.

Maslach, C. (1982). Burnout--The cost of caring. Englewood Cliffs, NJ: Prentice Hall.

Matteson, M.T. \& Ivancevich, J.M. 1987). Controlling work stress: Effective human resource and management strategies. San Francisco: JosseyBass.

Matteson, M. T. \& Ivancevich, J.M. (1982). Managing job stress and health: The intelligent person's guide. New York: The free Press.

Miller, W.C. (1979). Dealing with stress: A challenge for educators. Bloomington, IN: Phi Delta Kappa Educational Foundation.

Milstein, M.M. \& Golaszewski, T.J. (1985). Effects of organizationally based and individually based stress management efforts in elementary school settings. Urban Education, 19, 389-409.

Morris, J.E. \& Morris, G.W. (1980). Stress in student teaching. Action and Teacher Education, 4 (2), 57-62.

Murphy, J. (1996). Why privitization signals a sea of change in schooling. Educational Leadership, 54 (2), 60-62.

National Association of Independent Schools. (1997). NAIS statistics: 1994. Washington, DC: National Independent School Association. 
National Center for Education Statistics. (1993). Digest of education statistics, 1993. Washington DC: U.S. Government Printing Office.

Needle, R.H., Griffin, T., \& Svendsen, R. (1981). Occupational stress: Coping and health problems of teachers. Journal of School Health, 51, 175181.

Okebukola, P.A., \& Jegede, O.J. (1992). Survey of factors that stress science teachers and an examination of coping strategies. Science Education, $76,199-210$.

Phillips, E.L. (1982). Stress, health and psychological problems in the major professions. Washington, DC: University Press of America.

Pierce, C.M., \& Molloy, G.N., (1990). Relations between school type, occupational stress, role perceptions and social support. Australian Journal of Education, 34, 330-338.

Pierson, D.A. (1984). Perceived intensity of burnout among supportive service groups and a comparison teacher group as related to perceived need deficiencies, perceived role stress, and selected personal and professional variables and percepts. Dissertation Abstracts International, 44 (10), 3018A. Potts, J. (1996, June 28). A parents guide to charter schools. The Miami Herald, pp. F1-F2.

Pratt, J. (1978). Perceived stress among teachers: The effects of age and background of children taught. Educational Review, 30 (1), 3-14. 
Purkerson R.A. (1980). Stress and the beginning teacher--and the walls come tubling down. Action and Teacher Education, 42), 47-49.

Roberson, J.B., \& Rich, K.I. (1993). On the scene: A sounselor-led workshop for teachers to improve coping responses to the stress accompanying classroom appraisal visits. School Counselor, 40, 389-393.

Sarros, J.C., \& Sarros, T.C. (1992). Social support and teacher burnout. Journal of Educational Administration, 30, 55-69.

Selye, H. (1976). The stress of life (Rev. ed.). New York: McGraw-Hill.

Seyle, H. (1982). History of the stress concept. In L. Goldberger \& S. Breznitz (Eds.), Handbook of stress: Theoretical and clinical aspects (pp. 7-17). New York: Free Press.

Schwab, R.L., Iwanicki, E.F. (1982a). Perceived role conflict, role ambiguity, and teacher burnout. Educational Administration Quarterly, 18, 6074.

Schwab, R.L., Iwanicki, E.F. (1982b). Who are our burned out teachers? Educational Research Quarterly, 7, (2), 5-16.

Schwab, R.L., Jackson, S.E., \& Schuler, R.S. (1986). Educator burnout: Sources and consequences. Education Research Quarterly, 10 (3), 14-30. Shaw, S.F., Bensky, J.M., \& Dixon, B. (1981). Stress and burnout: A primer for special education and special services personnel. Reston, VA: Council for Exceptional Children.

Solman, R., \& Feld, M. (1989). Occupational stress: Perceptions of 
teachers in Catholic schools. Journal of Educational Administration, 27 (3), 55 68.

Speck, B.W. (1993). Defining stress as ethical conflict. The Bulletin, 56 (1), 34-37.

Starnaman, S.M., \& Miller, K.I., (1992). A test of a causal model of communication and burnout in the teaching profession. Communication Education, 41, 40-53.

Sutton, G.W., \& Huberty, T.J. (1984). An evaluation of teacher stress and job satisfaction. Education, 105, 189-192.

Swick, K.J. (1989). Stress and Teaching. Washington, DC: National Education Association.

Sykes, G., \& Elmore, R.F. (1989). Making schools more manageable. In J. Hannaway and R. Crowson, The politics of reforming school administration ( pp. 77-94). New York: Falmer Press.

Truch, S. (1980). Teacher bumout and what to do about it. Novato, CA: Academic Therapy Publications.

Turk, D.C., Meeks, S., \& Turk, L.M. (1982). Factors contributing to teacher stress: Implications for research, prevention, and remediation. Behavioral Counseling Quarterly, 2 (1), 3-25.

Virtue, J.R. (1992). Causes of teacher tumover in church-related schools in the American Association of Christian Schools. Unpublished doctoral 
dıssertation, Florida International University.

Washington, K.R. (1989). Controlling job stress: Some tips for urban teachers. School Organization, 9, 315-318.

Wilson, C.F. (1979). Wilson Stress Profile for Teachers. In S. Truch, Teacher burnout and what to do about it (pp. 103-105). Novato, CA: Academic Therapy Publications.

Young, T. (1980). Teacher stress: One district's approach. Action and Teacher Education, 4 (2), 37-40.

Zacherman, J.G. (1984). Relationship between stress, job involvement and teaching the handicapped. Dissertation Abstracts International, 44 (11), 32A. 


\section{APPENDIX A}

\section{TEACHER CONCERNS INVENTORY}

The following are a number of teacher concerns. Please identify those factors that cause you stress in your present position. Read each statement carefully and decide if you ever feel this way about your job. Then, indicate how strong the feeling is when you exm perience it by clrcling the approprate number on the 5-point scale. Il you have not experienced this feeling. or if the item is inappropriate for your position, circle number 1 (no strength; not noticeable). The rating scale is shown at the top of gach page.

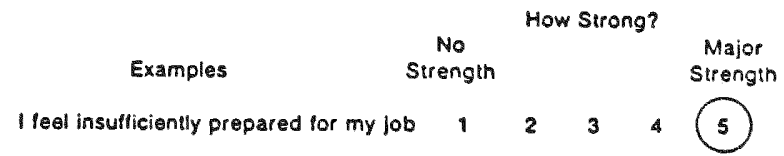

II you teet very stiongly that you are insufficiently prepared for your job, you would circle number 5 .

I feel that if I step back in either effort or commitment, I may bo seen as less competent.

(1) 2345

If you never feel this way, and the feeling does not have noticeable strength, you would circle number 1 .

\begin{tabular}{ccccccc}
\hline & 1 & 2 & 3 & 5 & \\
HOW & no & mild & medium & great & major \\
STHONG? & strength; & strength; & strongth; & strongth; & strength; \\
$?$ & not & barely & moderately & very & extremely \\
& noticeable & noticeable & noliceable & noticeable & noticeable & \\
\hline
\end{tabular}

1. I easily overcommit mysell

TIME MANAGEMENT

2. Decome impatient il others do things too slowly.

3. I have to try doing more than one thing at a time.

4. I have little time to pelax/enjoy the time of day.

5. I think about unrelated matters during conversations.

6. I feel uncomiortable wasting time.

7. There isn't enough time to get things done.

8. I rush in my speech.

$\begin{array}{rrrr}2 & 3 & 4 & 5 \\ 2 & 3 & 4 & 5 \\ 2 & 3 & 4 & 5 \\ 1 & 3 & 4 & 5 \\ 2 & 3 & 4 & 5 \\ 1 & 3 & 4 & 5 \\ 2 & 3 & 4 & 5 \\ 2 & 3 & 4 & 5\end{array}$

Add ltems 1 through 8 ; divide by 8 ; place score in the circle.

WOAK-AELATEO STRESSORS

9. There is little time to prepare lor my lessons/responsibilities.

10. Ther is too much work to do.

11. The pace of the school day is too fast.

12. My caseload/class is too big.

13. My personal priotities are being shortchanged due to time demands.

14. There is too much administrative paperwork in my job.

$\begin{array}{lllll}1 & 2 & 3 & 4 & 5 \\ 1 & 2 & 3 & 4 & 5 \\ 1 & 2 & 3 & 4 & 5 \\ 1 & 2 & 3 & 4 & 5 \\ 1 & 2 & 3 & 4 & 5 \\ 1 & 2 & 3 & 4 & 5\end{array}$

Add ftems through 14; divide by 6 ; place score in the circle.

\section{PROFESSIONAL DISTRESS}

15. Ilack promotion and/or advancement opportunities.

16. I am nop progressing in my job as rapidly as 1 would like.

17. I need mor status and respect on my job.

18. Ireceive an inadequate salary for the work $1 d o$.

19. I lack pecognition for the extra work andfor good leaching $\mid$ do.

$\begin{array}{lllll}1 & 2 & 3 & 4 & 5 \\ 1 & 2 & 3 & 4 & 5 \\ 1 & 2 & 3 & 4 & 5 \\ 1 & 2 & 3 & 4 & 5 \\ 1 & 2 & 3 & 4 & 5\end{array}$

Add ltems is through 19; divide by 5; place scor in the circle. 


\begin{tabular}{|c|c|c|c|c|c|}
\hline $\begin{array}{c}\text { HOW } \\
\text { STRONG? } \\
?\end{array}$ & $\begin{array}{c}1 \\
\text { no } \\
\text { strength: } \\
\text { not } \\
\text { noticeable }\end{array}$ & $\begin{array}{c}2 \\
\text { mild } \\
\text { trength; } \\
\text { bareiy } \\
\text { noticeablo }\end{array}$ & $\begin{array}{c}3 \\
\text { medium } \\
\text { strength; } \\
\text { moderately } \\
\text { noticaable }\end{array}$ & $\begin{array}{c}4 \\
\text { proat } \\
\text { trength; } \\
\text { very } \\
\text { noticeable }\end{array}$ & $\begin{array}{c}5 \\
\text { major } \\
\text { strength: } \\
\text { extromely } \\
\text { noticosble }\end{array}$ \\
\hline
\end{tabular}

DISCIPLINE ANO MOTIVATION

I leel irustrated...

20. ... because of discipline problems in my classroom.

21. ... having to monitor pupil bohavior.

22. ... because some students would do better it they tried.

23. ... attempting to teach students who are poorly motivated.

24. ... because of inadequate/poorly defined discipline problem.

25. ... when my authority is rejected by pupils/administration.

$\begin{array}{lllll}1 & 2 & 3 & 4 & 5 \\ 1 & 2 & 3 & 4 & 5 \\ 1 & 2 & 3 & 4 & 5 \\ 1 & 2 & 3 & 4 & 5 \\ 1 & 2 & 3 & 4 & 5 \\ 1 & 2 & 3 & 4 & 5\end{array}$

Add items 20 through 25; divide by 6 ; place score in the circle.

PROFESSIONAL INVESTMENT

26. My personal opinions are not sufticiently airod.

27. I lack control over decisions made about classroom/school matters.

28. I am not emotionally/inteliectually stimulated on the job.

29. Ilack opporiunities for protessional improvemant.

$\begin{array}{lllll}1 & 2 & 3 & 4 & 5 \\ 1 & 2 & 3 & 4 & 5 \\ 1 & 2 & 3 & 4 & 5 \\ 1 & 2 & 3 & 4 & 5\end{array}$

Add llems 26 through 29; divide by 4 ; place score in the circle.

EMOTIONAL MANIFESTATIONS

Irespond to stress...
30. ... by tealing insecure.
31. ... by feeling vulnerable.
32. ... by teeting unable to cope.
33. ... by teeling depressed.
34. ... by feeling anxious.

$\begin{array}{lllll}1 & 2 & 3 & 4 & 5 \\ 1 & 2 & 3 & 4 & 5 \\ 1 & 2 & 3 & 4 & 5 \\ 1 & 2 & 3 & 4 & 5 \\ 1 & 2 & 3 & 4 & 5\end{array}$

Add ttems 30 through 34; divide by 5 ; place score in the circle.

\section{FATIGUE MANIFESTATIONS}

I respond to stress...
35. ... by sleeping more than usual.
36. ... by procrastlnating.
37. ... by becoming latigued in a very short time.
38. ... with physical exhaustion.
39. ... with physical weakness.

$\begin{array}{lllll}1 & 2 & 3 & 4 & 5 \\ 1 & 2 & 3 & 4 & 5 \\ 1 & 2 & 3 & 4 & 5 \\ 1 & 2 & 3 & 4 & 5 \\ 1 & 2 & 3 & 4 & 5\end{array}$

Add ltems 35 through 39; divide by 5; place score in the circle.

\section{CAROIOVASCULAR MANIFESTATIONS}

Irespond to stress...

40. ... with feelings of increased blood pressure.

41. ... with feeling of heart pounding of racing.

42. ... with rapid and/or shallow breath.

$\begin{array}{rrrrr}1 & 2 & 3 & 4 & 5 \\ 1 & 2 & 3 & 4 \\ 1 & 2 & 3 & 4 & 5\end{array}$

Add ltems 40 threugh 42 ; divide by 3 ; place score in the circle. 


\begin{tabular}{|c|c|c|c|c|c|}
\hline $\begin{array}{c}\text { HOW } \\
\text { STAONG? } \\
?\end{array}$ & $\begin{array}{c}1 \\
\text { no } \\
\text { strength: } \\
\text { not } \\
\text { noticaable }\end{array}$ & $\begin{array}{c}2 \\
\text { mild } \\
\text { surength: } \\
\text { barely } \\
\text { noticeable }\end{array}$ & $\begin{array}{c}3 \\
\text { modium } \\
\text { atrongth; } \\
\text { moderately } \\
\text { noticeable }\end{array}$ & $\begin{array}{l}4 \\
\text { great } \\
\text { strength: } \\
\text { very } \\
\text { noticaable }\end{array}$ & $\begin{array}{c}5 \\
\text { major } \\
\text { strength; } \\
\text { extremely } \\
\text { noticeable }\end{array}$ \\
\hline
\end{tabular}

I respond to stress...

43. ... with stomach pain of extended duration.

44. ... with stomach eramps.

45. ... with stomach acld.

$\begin{array}{lllll}1 & 2 & 3 & 4 & 5 \\ 1 & 2 & 3 & 4 & 5 \\ 1 & 2 & 3 & 4 & 5\end{array}$

Add ftems 43 through 45 ; divide by 3 ; place score in the circle.

BEHAVIORAL MANIFESTATIONS

I respond to stress...

46. ... Dy using over-the-counter drugs.

47. . . by using prescription drugs.

48. ... by using alcohol.

49. ... by calling in sick.

$\begin{array}{lllll}1 & 2 & 3 & 4 & 5 \\ 1 & 2 & 3 & 4 & 5 \\ 1 & 2 & 3 & 4 & 5 \\ 1 & 2 & 3 & 4 & 5\end{array}$

Add llems 46 through 49; divide by 4; place score in the circle.

TOTAL SCORE (add all circles; divide by 10)

Your sex:

Your gge:

What level students do you teach?

Elementary

With what type of students do you work?

Which degrees do you have?

Do you and your peers support one another when needed?

Do you and your supervisors support one another when needed?
Demographic Variables

Number of years you have taught? How many students do you teach each day?

(circle the rest ol your answers)

Middle School

Secondary

Nonhandicapped

Bachelor's Master's

Handicapped

Doctorate

Yes No

Yes No 


\section{APPENDIX B}

July 17, 1966

William Creeden

Severn School

Water Street

Severna Park, MD 21146

Dear Mr. Creeden:

Thank you for granting me permission to include your faculty as participants in my doctoral research. While there are hundreds of studies on occupational stress in public schools, virtually none exist on the private sector. By agreeing to participate you are making a significant contribution to my research and $\mathrm{I}$ am profoundly grateful. In total, eight schools from six different states have agreed to be included in the study, representing a great deal of diversity in the private school community.

Attached is a copy of the Teacher Stress Inventory as well as some general comments regarding the instrument. There are three points of particular importance in this information. First, the inventory should take only about 15 minutes to complete. Secondly, it is suggested that teachers fill out the inventory at school. And Finally, as I indicated on the phone, the inventory is called a Teacher Concerns Inventory in order to prevent bias in responses.

While I hope to have a high rate of response from your school, participation by individual teachers is obviously voluntary. Your school will have a code number and will not be identified by name. While some demographic data is required from each teacher the inventory is completed anonymously in order to maintain complete confidentiality.

In early September I will contact you to get and exact count of your teachers. Part-time teachers and faculty whose primary responsibilities are administrative should not be included in your count.

Again, thank you for your participation in my study. I will be more than happy to share the results of my research with you when it is completed. If you have any questions please don't hesitate to call me at (305) 7592843 ext. 212.

Sincerely, John Davies 


\section{APPENDIX C}

September 20, 1996

William Creeden

Severn School

Water Street

Severna Park, MD 21146

Dear Mr. Creeden:

Enclosed are your copies of the Teacher Stress Inventory (TSI). The administration of the inventory can be done in a couple of ways. Please select the one that works best for your school. It can be given in a groups setting such as a faculty meeting or teachers may complete it individually in their classrooms or the faculty workroom. Part-time teachers and faculty whose primary responsibilities are administrative should not complete the inventory. While participation is voluntary I would appreciate any encouragement you might give your teachers to participate.

As you read in the instructions I sent to you this summer, it is important not to discuss the issue of teacher stress before administering the TS/ so that reactive effects are minimized. This is one of the reasons that the instrument is entitled the "Teacher Concerns Inventory" rather than "Teacher Stress Inventory." While instructions for scoring are provided on the inventory itself teachers need not do so. I am looking at composite, not individual scores, in order to develop a profile of teacher stress. I have included another copy of the administrative guidelines and would encourage you to read over them before handing out the inventories.

The inventories for each school are coded with a number in order to maintain confidentiality. I would ask that the inventories be completed by the end of October if possible. I have provided a large envelope with prepaid postage for mailing the completed instruments back to me.

Again, I would like to express by thanks for your participation in this study. As I noted this summer in our phone conversation, the literature on teacher stress is abundant, but very little is known about occupational stress in private schools. As one of the eight schools participating in this study you are making an important contribution to our understanding of what stress "looks like" in the private school. I look forward to sharing the results of my research when it is completed in the spring.

Should you have any questions please feel free to contact me at any time at (305) 259-2843 ext. 212.

Sincerely, John Davies 


\section{VITA}

\section{JOHN DAVIES}

August 27, 1953

1973

1975

1978-1979

1983

1984-1986

1986-1997

1987

1992

1989-1997
Born, Houston, Texas
A.A., Humanities
LaSalette Seminary
Altamont, New York

B.A., Philosophy

Merrimack College

North Andover, Massachusettes

History Teacher

St. Pius X High School

Houston, Texas

M.A. History

Texas A\&M University

College Station, Texas

History Teacher, Dean of Students

Allen Academy

Bryan, Texas

Director of Middle School

Miami Country Day School

Miami, Florida

Awarded the Dewitt and Vera Hooker Fellowship

Recipient of the C.K. Chamberlain Award from the East Texas Historical Association

Doctoral Student

Florida International University

Miami, Florida 


\section{PUBLICATIONS AND PRESENTATIONS}

Davies, J.P. (1990). A Comprehensive Models for Teaching Thinking in the Middle School. Paper presented at the meeting of the National Middle School Association, Long Beach, California.

Davies, J.P. (1991). TV and Transescent Social and Emotional Development. Iransescence: The Journal on Emerging Adolescent Education, 9 (2).

Davies, J.P. (1991). Science and the Sacred: The Evolution Controversy at Baylor, 1920-1929. East Texas State Historical Association, 29 (2).

Davies, J.P. (1992). Transescents and the Mass Media: The Need for a New Literacy. Paper presented at the meeting of the National Middle School Association, San Antonio, Texas.

Davies, J.P. (1983). The Impact of the Media Upon the Health of Early Adolescents. Journal of Health Education, 24 (6).

Davies, J.P., and Mee, C. (1993). The Media is the Message: Gender Identity. Mass Media, and the Young Adolescent Girl. Paper presented at the Transescent Seminar XIII, University of Wisconsin, Platteville, Wisconsin.

Davies, J.P. (1996). Educating Students in a Media-Saturated Culture. Technomic Press, Lancaster, Pennsylvania. 